\title{
MUERTES Y RESURRECCIONES DEL POSITIVISMO JURÍDICO: UNA CRISIS DE DOSCIENTOS ÂNOS DE DURACIÓN*
}

\author{
Luis Lloredo Alix ** \\ Universidad Autónoma de Chile \\ luislloredo@gmail.com
}

RESUMEN. El objetivo de este artículo es mostrar que el positivismo jurídico ha vivido en crisis desde su mismo nacimiento, a principios del siglo XIX, y no solo desde la oleada neoconstitucionalista. En primer lugar se examinarán los problemas de las aproximaciones conceptuales al problema del positivismo y se defenderá la necesidad de un acercamiento histórico para comprender la cuestión de si el iuspositivismo se encuentra verdaderamente obsoleto. En segundo lugar se pasará revista a las sucesivas crisis que ha experimentado esta corriente a lo largo de sus doscientos años de historia, y se verá cómo ha ido adaptándose a todos esos embates. Por último se argumentará que, desde ese punto de vista, el ataque post-positivista no representa una impugnación radical de sus planteamientos, sino una reorientación que corre pareja con transformaciones ideológicas profundas del orden global.

Palabras clave: positivismo jurídico, post-positivismo, crítica ideológica, crisis del positivismo jurídico, historia del positivismo jurídico.

\section{Deaths and Resurrections of Legal Positivism: a Two Hundred Years' Crisis}

ABSTRACT. The aim of this essay is to demonstrate that legal positivism has been submitted to criticism from its very beginning, at early $19^{\text {th }}$ century, and not only from the neoconstitutionalist wave. Firstly we will examine the inconveniences of the conceptual approach to the problem of legal positivism and we will sustain that a historical approach is needed to properly undertake the question regarding the alleged obsolescence of legal positivism. Secondly we will go over the continuous crisis that legal positivism has endured along its two-hundred years' history, and it will be shown how this current has adapted to all its purported refutations. Lastly we will argue that, from the above mentioned perspective, the criticism of post-positivism does not involve a radical rejection to legal positivism, but a re-orientation which goes parallel with profound ideological transformations in the global order.

\footnotetext{
* Fecha de recepción: 1 de agosto de 2016. Fecha de aceptación: 16 de febrero de 2017.

Este trabajo ha sido posible gracias al Proyecto Fondecyt 11140660 de la Comisión Nacional de Investigación Científica y Tecnológica (CONICYT). Agradezco a la Sociedad Chilena de Filosofía Jurídica y Social por darme la oportunidad de pronunciar una conferencia sobre el tema, y a los miembros del Área de Filosofía del Derecho de la Universidad Autónoma de Madrid por permitirme presentar un borrador de este artículo en su seminario. Asimismo, estoy en deuda con la Sala Regional del Tribunal Electoral de Monterrey (México), que también me invitó a impartir una ponencia sobre el tema.

*** Doctor en filosofía del derecho por la Universidad Carlos III de Madrid y académico docente investigador en la Universidad Autónoma de Chile.
} 
Keywords: legal positivism, post-positivism, ideological criticism, crisis of legal positivism, history of legal positivism.

\section{INTRODUCCIÓN}

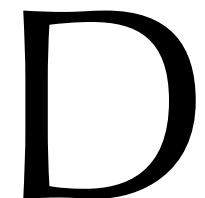

igámoslo sin dilación: el debate sobre el positivismo jurídico ha llegado a ser enormemente tedioso. Quizá se trate de uno de los ámbitos donde mayor virulencia teórica se ha desplegado en las últimas décadas, y es probable que estemos ante una de las polémicas más trilladas de la filosofía jurídica del siglo Xx. Como se intentará defender en las páginas siguientes, los motivos que me llevan a replantear el tema son de orden historiográfico y filosófico-político. Concretamente, se sostendrá que la presunta crisis del positivismo jurídico no es tan reciente como solemos pensar, ya que esta corriente ha estado recibiendo acusaciones de caducidad desde su mismo nacimiento. Creo que esta constatación historiográfica debería llevarnos a sospechar, por razones prudenciales, de aquelos planteamientos que se reclaman como sus superadores inapelables. Me parece que una afirmación semejante solo puede hacerse con suma cautela y teniendo en cuenta factores ideológicos distintos a los que habitualmente se han puesto sobre la mesa. En particular, se propondrá que los aprietos del positivismo jurídico no tienen que ver con la incorporación de la moral en los ordenamientos constitucionales contemporáneos, sino con un redimensionamiento de las relaciones entre derecho y política y con una transición profunda del orden global, que se ha traducido en la erosión irreversible de la soberanía estatal.

Dividiré la exposición en los siguientes apartados: primero se trazará una panorámica de la discusión en torno al positivismo, poniendo de manifiesto la logomaquia existente y la diversidad de tesis que se esconden bajo la misma rúbrica $(\$ 2)$; a continuación se hará una crítica de dos propuestas especialmente célebres e influyentes en este debate, las de Norberto BOBBIO y Herbert HART, para señalar sus deficiencias y justificar la necesidad de una aproximación genealógica (\$3); en tercer lugar se llevará a cabo una reconstrucción histórica de las impugnaciones sufridas por el positivismo a lo largo de los dos últimos siglos $(\$ 4)$; en cuarto lugar se defenderá la necesidad de una aproximación ideológica al problema, como único modo de explicar las causas de la crisis permanente del iuspositivismo $(\$ 5)$; por último se valorará la magnitud de los ataques (neo) constitucionalistas, para terminar proponiendo una forma alternativa de concebir la crisis del paradigma positivista $(\$ 6)$.

\section{LOS MIL ROSTROS DEL POSITIVISMO: LA BATALLA DE LAS ETIQUETAS}

Adentrarse por vez primera en el tema del positivismo jurídico es un quebradero de cabeza asegurado. Para empezar, la mayoría de los juristas profesionales utiliza la etiqueta de iuspositivismo a modo de sambenito: positivista sería ese jurista obtuso que vive ofuscado por el texto literal de la norma vigente, que jamás manifiesta preocupación por la ética, la justicia o el interés social, y que probablemente sacrificaría la lec- 
tura de un buen poema por el análisis ramplón del Boletín Oficial del Estado. Pero este prejuicio no solo proviene de los abogados «prácticos». De hecho, Norbert HOERSTER llegó a decir que en la filosofía del derecho alemana se consideraba «de buen tono» rechazar y condenar al positivismo jurídico (HOERSTER, 2000: 9). Esta afirmación debe ser cuidadosamente matizada, porque las cosas no siempre han sido así en todos los contextos geográficos y culturales. Por ejemplo, el enfoque positivista fue percibido como un soplo de aire fresco en la España post-franquista, dado que la ideología oficial del régimen había sido el nacionalcatolicismo y, por ende, la ortodoxia en las facultades de derecho fue el iusnaturalismo de corte religioso (RIVAYA, 2009). Algo similar podría decirse de muchos países latinoamericanos en los que la orientación positivista fue asociada con ideas más bien liberales o socialdemócratas, en clara oposición con las diversas dictaduras militares que azotaron la región (ATIENZA y RUIZ MANERO, 2007: 8-9). En estos casos, cabría afirmar que el iuspositivismo gozó de buena prensa durante al menos algunas décadas. Sin embargo, tengo la impresión de que las cosas han ido cambiando y que la penetración de la retórica neoconstitucionalista ha llegado a generar un nuevo sentido común, de acuerdo con el cual solo la testarudez, la inercia o la nostalgia podrían explicar el mantenimiento de las tesis positivistas tradicionales. Como irónicamente ha escrito Fernando ATRIA, «un nuevo fantasma recorre Europa: el fantasma del neo-constitucionalismo. Los poderes de la cultura jurídica europea han entrado en una santa alianza no para exorcizarlo sino para defenderlo e incluso exportarlo» (ATRIA, 2004: 118).

Así pues, las primeras incursiones en la polémica sobre el iuspositivismo resultan desconcertantes. Pero superado ese primer momento de estupor, y arrinconados los prejuicios que acabo de señalar, las cosas siguen siendo enormemente complejas. La logomaquia salta a primera vista: se ha hablado de positivismo legalista, normativista, historicista, analítico, formalista, institucionalista, realista, metodológico, teórico, ideológico, ético, normativo, corregido, sofisticado, incluyente, excluyente, incorporacionista, presuntivo, moderado, positivo, negativo, sociologista o psicologista, entre otras etiquetas que cabe encontrar en la literatura especializada (OTT, 1992: 32-103; ESCUDERO, 2004: 150-198; GONZÁLEZ VICÉN, 1979: 47-140). En algunas ocasiones estos calificativos son intercambiables, como sucede con los de incluyente e incorporacionista. En otras ocasiones, tales epítetos se dirigen a aspectos diversos de una teoría - aunque eventualmente complementarios- y, en ese sentido, pueden acumularse en un mismo autor sin estridencias. Sin embargo, lo que ocurre más a menudo es que existen discrepancias profundas entre los representantes del positivismo jurídico. Esta logomaquia, producto de dichas desavenencias, ha dado pie a numerosos propósitos de clarificación del canon positivista. Dado lo profuso de la discusión, no me parece posible realizar una panorámica exhaustiva en este momento, pero creo que sí conviene señalar algunos hitos relevantes.

Probablemente el pistoletazo de salida para este proceso de autodefinición tuvo lugar en 1958, como consecuencia de un artículo publicado por Herbert HART, en el que este propuso distinguir cinco significados distintos de la locución «positivismo jurídico». El positivismo sería así una corriente que sostiene cosas muy distintas, no necesariamente compatibles entre sí: 1) que el derecho está compuesto por mandatos humanos; 2) que no existe una conexión necesaria entre el derecho y la moral; 3) que el análisis de los conceptos jurídicos es la tarea principal de la teoría jurídica, y que 
dicha actividad debe desvincularse de otras investigaciones de naturaleza histórica o sociológica; 4) que el ordenamiento jurídico es un sistema cerrado, del que pueden extraerse decisiones correctas para los casos concretos con el mero auxilio del razonamiento lógico, y sin necesidad de apoyarse en consideraciones éticas, políticas o sociales, y 5) que no es posible establecer juicios morales mediante pruebas empíricas o argumentaciones racionales (HART, 1958: 601-602). Se trata de tesis que, en efecto, han sido defendidas por muchos iuspositivistas a lo largo de la historia: el imperativismo es reconocible en la primera; casi cualquier variante del positivismo es identificable en la segunda; la jurisprudencia analítica, las teorías de los conceptos jurídicos fundamentales o el realismo genovés son manifestaciones de la tercera; la jurisprudencia de conceptos o la escuela de la exégesis son un reflejo de la cuarta; y el no cognitivismo se deja ver en la quinta. En algunas ocasiones, como el mismo HART señalaba, varias de estas tesis se dan simultáneamente en un autor, mientras que otras veces las encontramos de forma independiente.

Ahora bien, en ese mismo artículo, HART nos advertía sobre la posibilidad de añadir otros significados. Y tenía razón, porque solo dos años más tarde, en 1960, Norberto BOBBIO y Alessandro PASSÉRIN D'ENTREVES organizaron un célebre congreso acerca del positivismo jurídico en la ciudad de BELLAGIO. El propósito de este encuentro era trazar un mapa de la cuestión, involucrando a iusfilósofos continentales y anglosajones, con el ánimo de identificar los diversos sentidos con los que se manejaba la expresión. De acuerdo con SHUMAN y FALK, en el evento se pusieron de manifiesto ocho formas distintas de emplearla: 1) el iuspositivismo es una teoría que entiende el derecho como un conjunto de reglas dictadas por el Estado, y la totalidad de dichas reglas debe ser coherente; 2) el iuspositivismo es una teoría que atribuye al Estado la exclusividad en la formulación de normas jurídicas, insistiendo así en la fuente humana —no trascendental — del derecho; 3 ) el iuspositivismo es una rúbrica que comprende a la jurisprudencia analítica inglesa, la jurisprudencia de conceptos alemana, la escuela de la exégesis francesa, la teoría kelseniana, el realismo jurídico norteamericano y el escandinavo; 4) el iuspositivismo es el trasunto jurídico de dos grandes movimientos filosóficos: la teoría de August COMTE y el positivismo lógico del Círculo de Viena; 5) el iuspositivismo es una teoría que incorpora las siguientes ideas: el derecho y la moral son órdenes normativos independientes, el derecho es un conjunto de mandatos estructurados de forma autoritativa, la validez de las normas jurídicas depende de criterios procedimentales, el derecho natural no existe, los valores morales no son cognoscibles; 6) el iuspositivismo es una teoría que ciñe su objeto de estudio a las normas jurídicas formales y que, por tanto, se distingue de la jurisprudencia sociológica; 7) el positivismo jurídico es una doctrina que separa el derecho de la moral, y 8) el positivismo jurídico no es una teoría formal (SHUMAN y FALK, 1961).

Como puede intuirse a tenor de este abigarrado elenco, lo que SHUMAN y FALK hicieron fue dejar constancia de los múltiples significados que los participantes del congreso habían utilizado, pero no elaboraron la información de manera sistemática. Si lo observamos con mirada crítica, nos damos cuenta de que en esas ocho acepciones se entremezclan tesis que quizá no deberían ir juntas, que algunas se repiten en varios puntos, que unas son descriptivas y otras prescriptivas, que algunas son contradictorias entre sí, o que algunas simplemente se refieren a aspectos accidentales del paradigma. En definitiva, se trata más bien de un totum revolutum que de una propuesta 
de definición del iuspositivismo. Ahora bien, lo importante de BeLlagio no fue el contenido de lo que allí se discutió o los eventuales acuerdos a los que llegaron sus participantes, sino la toma de consciencia respecto a la variedad de posiciones que se englobaban bajo la misma etiqueta. En ese sentido, el congreso fue un hito para el proceso de desbroce y clasificación que se dio a partir de entonces. En efecto, como ha señalado Genaro CARRIó, al «espíritu de Bellagio» se pueden retrotraer las siguientes publicaciones: Aspetti del positivismo giuridico de BoBBIO (1961), The Concept of Law de HART (1961), El concepto de validez y el conflicto entre el positivismo jurídico y el derecho natural de Alf Ross (1961) y Che cos'è il positivismo giuridico de Uberto SCARPELLI (1965) (CARRIÓ, 1981: 22). A continuación analizaré dos de las más célebres definiciones del positivismo que se hicieron a partir de entonces.

\section{UNA CRÍTICA A LAS PROPUESTAS DE BOBBIO Y HART: LA DIFICULTAD DE HALLAR UN CONCEPTO UNITARIO DE POSITIVISMO}

De todas las propuestas surgidas tras el congreso de BELLAGIO, conviene que nos detengamos primero en la de BOBBIO, porque se trata de uno de los intentos de clarificación que más éxito han cosechado. Me refiero a la celebérrima distinción entre el positivismo como «modo de aproximarse al estudio del derecho», como una «determinada teoría o concepción del derecho» o como una «ideología de la justicia», de donde se desprende la habitual tripartición entre positivismo metodológico, teórico e ideológico (Воввіо, 1977: 101-126). De acuerdo con BоввіO, el positivismo metodológico entrañaría una aproximación al fenómeno jurídico que diferencia con nitidez entre el derecho que es y el derecho que debe ser, entre el derecho como hecho y el derecho como valor, o entre el derecho real y el derecho ideal. Se trata, por tanto, de una actitud de neutralidad valorativa respecto al objeto de estudio. El positivismo teórico implicaría un posicionamiento más sustantivo, ya que identifica al derecho con una serie de rasgos, que grosso modo pueden reconducirse a la idea del Estado como agente monopolizador de la fuerza: la teoría de la coacción, la concepción del ordenamiento como un sistema pleno y coherente, la visión de la interpretación jurídica como un proceso mecánico y la descripción de las normas como mandatos o imperativos. El positivismo ideológico, en fin, sostendría algo mucho más fuerte aún: que todo orden jurídico positivo es justo per se. Ya se ha escrito mucho sobre esta diferenciación y no es momento de entrar en todos sus pormenores, pero sí estimo necesario hacer dos apuntes críticos.

El primero de ellos tiene que ver con el excesivo grado de abstracción que implica, cosa que se logra al precio de deformar drásticamente los perfiles de las teorías y los autores reales. Es muy difícil encontrar, por ejemplo, un filósofo que quepa dentro de lo que BOBBIO denominaba positivismo como ideología, al menos en la variante extrema de dicha corriente, que supuestamente identificaba al derecho positivo con la justicia (BoBBIO, 2005: 27) ${ }^{1}$. También es ficticia la pretensión de hallar autores que

1 BobBio aludió a las teorías del derecho del más fuerte como ejemplo de este reduccionismo tan brutal, pero basándose para ello en el retrato que Platón nos legó del sofista TrasímaCO (BOBBIO, 1996: 238). Sin em- 
asuman el positivismo en su aspecto metodológico, sin a la vez suscribir uno o varios de los elementos que el turinés asociaba al positivismo como teoría. En efecto, las distinciones entre el derecho que es y el derecho que debe ser casi siempre se llevan a cabo identificando al derecho «real» con el derecho estatal, por lo que el positivismo metodológico coincide en la mayoría de las ocasiones con alguna modalidad de positivismo teórico. Por otra parte, los rasgos que BOBBIO atribuía al positivismo teórico casi nunca se dan de forma conjunta en autores concretos, salvo quizá en algún representante de la escuela de la exégesis. De hecho, se suele decir que el positivismo teórico equivale a lo que normalmente llamamos formalismo, pero el formalismo así definido resulta inservible para aprehender las ideas de la jurisprudencia de conceptos, ya que esta no aceptaba la tesis de la coactividad o la supremacía de la ley como fuente de derecho. Resultaría de ello que uno de los momentos estelares del formalismo jurídico queda fuera de los criterios de formalismo à la $\mathrm{BOBBIO}^{2}$. A su vez, por poner un último ejemplo, las características del positivismo metodológico hacen que tanto un realista como un formalista quepan dentro de dicha definición, porque ambos tienden a demarcar con precisión el derecho como hecho del derecho como valor; la diferencia radicaría en qué entiende cada uno de ellos por «hecho» y por «valor». En suma, creo que la tripartición de BOBBIO no sirve para abrazar las teorías realmente existentes, que genera equívocos y que no resulta clarificadora para entender divisiones significativas dentro del paradigma positivista.

El segundo reproche que se le podría hacer a esta clasificación tiene que ver con la cuestión de la ideología. El tema de la ideología es uno de los más espinosos de la filosofía y las ciencias sociales, pero también uno de los campos de debate más interesantes que hoy existen en el mundo de las ideas. Hay muchas definiciones de ideología, desde las que tienen un cariz fundamentalmente epistemológico, en la estela de la doctrina de los idola de Francis BACON o de aquellos que Napoleón denominó con desprecio «ideologues», hasta las que se ubican con más decisión en el terreno filosófico-político (LENK, 2000: 9-46). Ambas dimensiones, no obstante, están entretejidas en la mayoría de las teorías contemporáneas. Tanto la noción de paradigma científico de KuHN, como la idea de episteme de Foucault (WEINERT, 1982), tanto el concepto de inconsciente de FrEUD como el sentido de lo fantasmático en ŽižEK (ŽIŽEK, 1992) —entre otros ejemplos- son reverberaciones de la cuestión de la ideología. Pese al tradicional aislamiento de la cultura jurídica, estas reverberaciones también han alcanzado a la filosofía del derecho, donde este asunto ha tenido episodios notables. El realismo

\footnotetext{
bargo, sabemos que PLATÓN deformó pro domo sua las ideas de los sofistas y los filósofos presocráticos, por lo que su interpretación de TRASíMACO no resulta del todo fiable (MENZEL, 1922). El otro ejemplo de positivismo ideológico aducido por BOBBIO es HoBBES. Este caso es más escurridizo, pero tampoco me parece adecuado considerarlo como positivista. De hecho, a juicio de HoBBEs, el deber absoluto de obediencia al orden legal era un precepto del derecho natural. En consecuencia, el presunto positivismo ideológico que BoBBIO le achacaba no era sino una manifestación de su concepción iusnaturalista (MURPHY, 1995).

${ }^{2}$ Las ideas de la jurisprudencia de conceptos son variables en función de los autores y de la época. En lo que se refiere a la teoría de las fuentes, SAVIGNY sostenía que la primacía debía recaer en la doctrina como intérprete privilegiada de la costumbre. Más adelante, JHERING criticaría a SAVIGNY por haber minusvalorado el papel de la legislación, pero ese era ya el segundo JHERING (WILHELM, 1958). Respecto a la teoría de la coactividad, tampoco me parece que se acomode a la jurisprudencia de conceptos: la metafísica idealista de PUCHTA o el primer JHERING desembocaba en una visión de los conceptos como entidades productivas de normas jurídicas, con independencia del apoyo que estas recibieran de la autoridad (JHERING, 2013: 234-275).
} 
jurídico escandinavo, por ejemplo, desplegó una crítica demoledora a la naturaleza ideológica de numerosas instituciones del derecho occidental —el derecho subjetivo, la autonomía de la voluntad, el deber jurídico, etc.- con base en una aproximación epistemológica que hunde sus raíces en el pensamiento de Axel HÄGERSTROM (HIERRO, 2008). La teoría jurídica soviética, por su parte, desarrolló un sólido acercamiento político a la cuestión de la ideología, pero no solo denunciando el contenido burgués de las normas — esta es la óptica de Piotr STUčKA—, sino también poniendo al descubierto el sesgo ideológico de las formas jurídicas, de los conceptos, las clasificaciones o las construcciones dogmáticas pretendidamente generales: este era el objetivo de Eugeni PAŠUKANIS (PAŠUKANIS, 1976). También los Critical Legal Studies pusieron sobre la mesa el tema de la ideología, haciendo hincapié en la construcción clasista, racial o patriarcal del derecho, y desvelando el trasfondo conservador de las teorías jurídicas tradicionales (PÉREZ LLEDÓ, 1996). Toda esta problemática es fundamental en relación con el iuspositivismo, pues se trata de una corriente que ha evolucionado conforme a las derivas ideológicas de los últimos dos siglos. En particular, me parece imprescindible incorporar la mirada epistemológico-política para desenmascarar los sesgos implícitos de la filosofía positivista o el currículum oculto que esta ha contribuido a imponer inconscientemente en la enseñanza de la teoría del derecho (LLOREDO, 2015: 209-227). Sin embargo, la noción bobbiana del positivismo ideológico ignora por completo este acercamiento a la cuestión de la ideología y, en ese sentido, emborrona y empobrece un debate que debería afrontarse con mayor profundidad.

Ahora bien, la de BOBBIO es solo una de las tentativas que se han sugerido para intentar poner orden en la miríada de significaciones que se asocian al positivismo jurídico. Probablemente, la propuesta de HART sea la más difundida en la filosofía del derecho contemporánea. Según el filósofo inglés, el iuspositivismo incorpora tres tesis básicas que todo autor debería mantener para ser considerado como un representante legítimo del paradigma: la tesis de las fuentes sociales, la tesis de la separabilidad entre derecho y moral y la tesis de la discrecionalidad judicial (HART, 1990). La primera afirma que las fuentes del derecho no son de naturaleza ideal, y que el sustento de la validez de las normas jurídicas puede identificarse en un hecho social: el legislador, el juez o, en general, una convención social. La segunda afirma que derecho y moral son órdenes conceptualmente separables, puesto que la validez jurídica no depende de la satisfacción de un determinado estándar de moralidad, sino de su conformidad con una regla de reconocimiento que, en última instancia, reenvía a la mencionada convención. La tercera, en fin, sostiene que los jueces tienen un determinado margen de discrecionalidad a la hora de decidir sobre los casos denominados difíciles. De acuerdo con HART, cualquier teoría positivista debería estar comprometida con estas tres tesis para poder ser concebida como tal. De hecho, fueron estas ideas las que DwORKIN eligió como blanco de sus ataques contra el paradigma iuspositivista en su conjunto.

La popularidad de esta aproximación al asunto del positivismo es enorme. Sin embargo, creo que volvemos a estar ante una definición discutible, sobre todo en lo que atañe a la tesis de la discrecionalidad. En efecto, si bien es cierto que las principales teorías positivistas del siglo XX se acomodan sin aprietos a la horma propuesta por HART, no sucede lo mismo con el iuspositivismo decimonónico. Tanto la escuela de la exégesis como la jurisprudencia de conceptos habrían rechazado dicha tesis, porque ambas mantuvieron una concepción cerrada del sistema jurídico, a saber: la idea de 
un ordenamiento pleno y coherente, que se integra a sí mismo sin necesidad de recurrir a intromisiones extrajurídicas y que prevé una única respuesta correcta para cada situación (LOSANO, 2002: 167 y ss.). En el caso de la escuela de la exégesis, esto era una consecuencia del espíritu cesarista con que se impuso el código napoleónico, cuyo propósito político era erigir un derecho pretendidamente infalible. Para ello se promocionó una ciencia jurídica basada en el comentario literal del código y la interpretación estrictamente silogística de sus disposiciones. En línea con tales pretensiones, se eliminaron también los estudios filosóficos e históricos de las facultades de derecho (FAssò, 2006: 17-21). En el caso de la jurisprudencia de conceptos, el resultado al que arribaron fue similar, aunque partiendo de presupuestos filosóficos distintos. De lo que se trataba era de construir una ciencia jurídica tan sofisticada que ni siquiera fuese necesario el legislador, merced a la identificación de una serie de supra-conceptos jurídicos obtenidos mediante inducción a partir de las prescripciones inferiores del derecho vigente. Estos supra-conceptos permitirían deducir nuevas normas para resolver cualquier desafío imaginable. El sistema así configurado quedaba estructurado a través de una férrea trabazón lógico-deductiva, de modo que era impensable la existencia de lagunas, antinomias o discrepancias interpretativas. La discrecionalidad, por tanto, tampoco cabía en los esquemas de la jurisprudencia de conceptos. Así las cosas, resulta que dos de las variantes más señeras del positivismo decimonónico quedan fuera de la definición de HART. Esto plantea una aporía frente a la que solo se me ocurren tres posibles salidas, todas ellas insatisfactorias.

La primera posibilidad consistiría en rebajar las exigencias establecidas por HART y descartar la característica de la discrecionalidad judicial como definitoria del positivismo. Esto nos llevaría a una concepción mínima del paradigma, que quedaría identificado por la tesis de la separabilidad entre derecho y moral y por la teoría de las fuentes sociales. Pero esto sigue siendo problemático porque, para empezar, es dudoso que las teorías positivistas del siglo XIX tuvieran una visión tan estricta de la separación entre lo ético y lo jurídico. Al menos en el caso de la escuela alemana, el estatus de los conceptos jurídicos resultaba muy ambivalente: estos eran obtenidos mediante inferencia a partir de las prescripciones particulares del ordenamiento - es decir, arrancando del derecho positivo- pero terminaban quintaesenciándose en entidades conceptuales de naturaleza ética que poseían validez con independencia del derecho vigente (R. DREIER, 1993). Podríamos entonces prescindir del rasgo de la separabilidad, pero entonces llegaríamos a una definición aún más raquítica del positivismo, según la cual positivistas serían todas aquellas teorías que reconozcan el origen «social» del derecho. Existen varias formas de entender el significado de «fuentes sociales»y, como ha mostrado Juan Carlos BAYÓN, no se trata en absoluto de una idea trivial (BAYÓN, 2002). Sin embargo, es una tesis que apenas dice nada y que, por tanto, condena al iuspositivismo a la irrelevancia teórica (ATIENZA y RUIZ MANERO, 2007: 21).

La segunda posibilidad consistiría en restringir las tesis de HART al positivismo jurídico del siglo XX, pero esta tampoco me parece una salida airosa. Primero, porque ello nos obligaría a trazar una diferencia entre un positivismo «en sentido pleno» y uno «primitivo», con lo que incurriríamos en el clásico prejuicio de ver la historia como un proceso tendente siempre a mayores grados de depuración. Además, si tenemos en cuenta que Luigi FERRAJOLI ya ha apostado por distinguir entre un positivismo constitucionalista y un «paleo-positivismo» del Estado legislativo de derecho 
(FERRAJOLI, 2011: 16), creo que una diferenciación ulterior no haría sino arrojar mayor confusión a un debate por sí mismo enrevesado. Por otra parte, discriminar entre un positivismo del siglo XIX y otro del XX levantaría una frontera artificiosa sobre la base de las cuestiones de la separabilidad y la discrecionalidad judicial, encubriendo lazos de continuidad fundamentales y estableciendo barreras que en realidad son enormemente porosas. Pensemos, por ejemplo, en cómo las ideas del segundo JHERING se encuentran desarrolladas en los diversos antiformalismos del siglo XX, entre ellos el realismo jurídico. Por último, una compartimentación semejante traería problemas a la hora de clasificar a la jurisprudencia analítica inglesa, que sí defendió la separación entre derecho y moral y que, en consecuencia, tiene una prolongación evidente en los positivismos del siglo XX. Desde luego, se puede optar por una definición estipulativa, restringiendo el positivismo a sus modalidades contemporáneas y a la jurisprudencia analítica, pero esto tiene un sesgo anglosajón que conllevaría dejar fuera a corrientes que siempre fueron concebidas como positivistas en la cultura continental.

La tercera posibilidad consistiría en dictaminar el carácter espurio de algunas teorías que solo serían positivistas en apariencia, ya que en realidad incorporan un planteamiento metafísico idealista. Esta estrategia ha sido utilizada por muchos autores para sostener que la escuela histórica no fue sino un epígono del iusnaturalismo: NINO, por ejemplo, llegó a hablar de iusnaturalismo historicista (NINO, 2003: 29). No obstante, creo que esta apreciación se asienta en varios equívocos. El primero es que los conceptualistas alemanes no se propusieron la tarea de edificar un catálogo de conceptos jurídicos universales, válidos para todo tiempo y lugar, sino que aspiraron más bien al momento de la generalidad, es decir, a diseñar un elenco de nociones jurídicas básicas para un sistema jurídico determinado (FALZEA, 1992: 62 y ss.). En la traducción española de El sistema de derecho romano de SAVIGNY, auspiciada por un iusnaturalista como Manuel DURÁN Y BAS, se comete a menudo el error de traducir «general» por «universal», lo que probablemente haya contribuido a generar dicha confusión (LLOREDO, 2014: 257-258). El segundo equívoco tiene que ver con el modo en que se obtienen dichas nociones. Para la escuela histórica se trata de una tarea artificial: los conceptos no se descubren y la ciencia jurídica no procede deductivamente desde arriba hacia abajo, como en la tradición del derecho natural, sino que estos se construyen mediante operaciones de inducción escalonada. El tercer equívoco tiene que ver con la supuesta equivalencia entre la idea de «espíritu del pueblo» y las típicas instancias trascendentales que el iusnaturalismo identificaba como fuentes del derecho. Se trata de un error, porque SAVIGNY no empleó la expresión «espíritu del pueblo» de la forma en que se le achaca: solo la encontramos en su obra a partir de 1840 —antes solía usar las locuciones de «convicción común» o «conciencia común» del pueblo (SAVIGNY, 1814: 8; CONTRERAS, 2005: 72) —, y nunca lo hizo con la pretensión de designar a una especie de agente que dictaba el contenido del derecho a modo de deidad, sino con ánimo metafórico.

En suma, ninguna de estas alternativas me parece convincente para soslayar las aporías a las que nos abocaba el enfoque de HART. Al igual que en el caso de BOBBIO, el propósito de encontrar una serie de tesis definitorias del positivismo se ve condenado al fracaso, ya que ninguna consigue reducir a una unidad coherente y precisa la multiplicidad de posiciones que se han desplegado en los dos últimos siglos. Por eso, como se proponía en la introducción, considero imprescindible recurrir a una mirada 
historicista que explique las características de este paradigma en clave evolutiva, en la línea de los clásicos trabajos de Felipe GonZález VicÉn (GONZÁlez VicÉN, 1979; 1984). A continuación optaré por este tipo de aproximación, con el objetivo de resaltar las sucesivas crisis experimentadas por dicha corriente.

\section{CRISIS Y REINVENCIONES DEL IUSPOSITIVISMO: UNA APROXIMACIÓN COMPREHENSIVA E HISTORICISTA}

La historia del positivismo es un reguero de disputas, impugnaciones, caídas y reconstrucciones. A continuación pretendo mostrar que, desde el mismo inicio del siglo XIX, se ha diagnosticado la obsolescencia del positivismo y se ha pronosticado su inmediata superación. A veces estas acusaciones se han producido desde plataformas que han pretendido situarse fuera de la órbita del paradigma, aun cuando hoy las percibimos como manifestaciones consustanciales del mismo. Otras veces, en cambio, las críticas se han elevado desde el mismo interior del positivismo jurídico, por parte de autores o corrientes que han reprochado a sus predecesores el no ser suficientemente positivistas o el ser prolongaciones encubiertas del iusnaturalismo. Tendríamos, entonces, una larga retahíla de críticas desde dentro y desde fuera del paradigma. Lo interesante es que, en todos los casos, el positivismo logró rehabilitarse mediante una sorprendente capacidad de adaptación. No en vano, Horst DREIER ha sostenido que, al igual que se suele decir del iusnaturalismo, podría hablarse de un «eterno retorno del positivismo» (H. DREIER, 2007).

El primer embate externo contra el positivismo lo encontramos indirectamente en el propio SAVIGNY, que desplegó una crítica demoledora contra el legalismo francés en su célebre escrito de 1814, De la vocación de nuestro siglo para la legislación y la ciencia jurídica. Pese a que SAVIGNY no utilizaba la locución «iuspositivismo», en su escrito existen múltiples alusiones al peligro de reducir la ciencia jurídica al derecho positivo de impronta legislativa, ya que, a su juicio, el origen de las normas jurídicas se encontraba en el sentimiento y la historia de los pueblos (SAVIGNY, 1814: 8-17): de ahí su crítica contra el Code de Napoleón y contra la propuesta de codificación para Alemania. Años atrás, en los trabajos preparatorios de su Metodología jurídica, SAVIGNY también había descargado su ira contra el formalismo, refiriéndose con ello a las teorías que pretendían construir la ciencia jurídica sin apoyarse en la historia del derecho y que, por ende, configuraban un sistema cuya realidad era «puramente formal o lógica» (SAVIGNY, 1993: 101). Tanto el antilegalismo como el antiformalismo deben entenderse como pilares del proyecto filosófico de SAVIGNY, que consistía en ofrecer una suerte de tercera vía frente al iusnaturalismo racionalista del siglo XVIII y frente al positivismo ramplón de los primeros compases del siglo XIX. Esto se confirma cuando leemos un célebre discurso pronunciado por Otto VON GIERKE en 1882, en el que presentaba a la escuela histórica como alternativa frente al «positivismo obtuso» y frente al «apriorismo» del derecho natural (GIERKE, 1883: 11). Hoy solemos considerar a SAVIGNY como representante del positivismo jurídico, dado que su escuela fue responsable de introducir la idea de la historicidad del derecho en la conciencia jurídica occidental. Sin embargo, esto no se veía así a principios y mediados del siglo XIX, y menos en Alemania, donde no es extraño encontrar a SAVIGNY catalogado dentro de la doctrina 
de la «naturaleza de las cosas». Así lo interpretó Gustav RADBRUCH en pleno siglo XX (RADBRUCH, 1960; FOLJANTY, 2013: 196 y ss.).

El tópico de la tercera vía es una constante en la historia que nos ocupa. Este es el caso del realismo jurídico, especialmente el escandinavo, que también se planteó como una forma de superar la dicotomía entre iusnaturalismo y positivismo. Podemos apreciarlo en el pensamiento de Karl OliveCronA, para quien la disyuntiva fundamental era otra: la que enfrentaba al realismo con el idealismo. De acuerdo con esta nueva bipartición, tanto las teorías del derecho natural como las concepciones positivistas debían ser agrupadas dentro del idealismo. En efecto, en opinión de OliveCrOnA, el positivismo surgió con la aspiración de demoler las falsas especulaciones del derecho natural, pero terminó incurriendo en posiciones igualmente metafísicas. Y ello por dos razones. Por un lado, porque una de las orientaciones más características que asumió el positivismo, la teoría general del derecho, cayó en el viejo anhelo iusnaturalista de buscar un breviario de principios jurídicos universales. Con ello, a su juicio, el positivismo se deslizó inconscientemente hacia el idealismo. Por otro lado, porque los positivistas trataron de reducir el derecho al Estado o, en casos más sofisticados, a la voluntad de una autoridad efectivamente hegemónica en una comunidad dada. Pero eso, pensaba OLIVECRONA, implicaba quintaesenciar la noción de autoridad, cayendo en una especie de esencialismo de la voluntad, como si hubiera un poder preexistente a toda relación político-jurídica. A juicio del pensador sueco, la única respuesta realista al problema de la existencia del derecho pasaba por concebir a este como un fenómeno que se alza sobre un «conjunto de regularidades psicológicas» o «de hechos sociales», y no como el fruto de una voluntad exterior que sostiene la eficacia del derecho desde fuera del derecho (OliveCronA, 2013: 248-263). La cuestión de si el realismo es o no una manifestación del positivismo es ciertamente problemática en la literatura especializada. Acabamos de ver que, para muchos de sus representantes, el realismo jurídico era una manera de esquivar la dualidad de las dos escuelas tradicionales. Sin embargo, para muchos iusfilósofos actuales no es sino una profundización de la crítica al derecho natural que ya había iniciado el positivismo decimonónico (GONZÁLEZ VICÉN, 1979: 190 y ss.). Nos volvemos a encontrar así con otro caso de impugnación externa del positivismo, que sin embargo hoy tendemos a percibir como ejemplo de evolución interna del paradigma.

A la vez que se desarrollaba el realismo jurídico, en diversas partes del mundo surgieron numerosos movimientos que solemos calificar con la etiqueta de antiformalistas. Me refiero a la jurisprudencia sociológica, a la escuela del derecho libre de los países germánicos, a la libre investigación científica de François GÉNY o al solidarismo de Duguit en Francia y, en general, a las teorías sociologistas que florecieron en las primeras décadas del siglo XX. Al igual que el realismo, muchas de estas corrientes nacieron con la voluntad de subvertir la disyuntiva entre iusnaturalismo y positivismo jurídico. Sin embargo, en algunos casos los exponentes de esta oleada se vieron a sí mismos como rehabilitadores del derecho natural. Un caso llamativo es el de Hermann KANTOROWICZ, buque insignia del movimiento del derecho libre, que trató de presentar a la nueva escuela como un resurgir del iusnaturalismo. A su modo de ver, la hornada de teóricos que, a inicios del siglo XX, estaban criticando el dogma del estatalismo de las fuentes del derecho, la concepción mecanicista de la interpretación judicial o el exceso de logicismo de la ciencia jurídica, se caracterizaba por una censura del legalis- 
mo y por una correlativa resurrección de la aproximación ética al fenómeno jurídico, cosa que él equiparaba a las teorías del derecho natural. En realidad, KANTOROWICZ estaba agrupando bajo un mismo paraguas a autores muy dispares: tardo-iusnaturalistas como Rudolf STAMMLER, pioneros de la sociología jurídica como Eugen EHRLICH, partidarios de la jurisprudencia de intereses como Max RüMELIN y exponentes del derecho libre stricto sensu como Ernst STAMPE (KanTOROWICZ, 1906: 10-12). Pero se trata de una mezcolanza injustificada (RÜCKERT, 2011) que poco tiene que ver con un rebrote del derecho natural. Obviando la incomodidad que la mayoría de estos autores habría sentido al verse catalogados de dicha manera, es que ni siquiera el pensamiento de KANTOROWICZ se deja alinear en una cosmovisión iusnaturalista: su objetivo no era restablecer la creencia en una serie de valores superiores al ordenamiento jurídico que determinan su validez, sino criticar la reducción del derecho al derecho estatal, promocionar un papel más creativo del juez y reconectar el derecho con la experiencia social. Todas estas son ideas que, como bien vio Guido FAssò, no deben entenderse como un renacimiento del derecho natural, sino como una tentativa de sociologizar el pensamiento jurídico, una operación característica de muchas concepciones de la primera mitad del siglo XX (FASSÒ, 2006: 199). He aquí, por tanto, otro caso de refutación pretendidamente externa del positivismo, que sería más prudente considerar como ejemplo de adaptación interna.

La mención de Rudolf STAMMLER es interesante, porque la siguiente parada de nuestro recorrido son aquellas teorías que pretendieron restaurar el credo iusnaturalista e impugnar las «unilateralidades» del positivismo jurídico en diversos momentos del siglo XX. Se trata de un tema complejo que no puede abordarse ahora con exhaustividad, pero me parece que deben hacerse al menos dos apreciaciones.

La primera es que, en realidad, las rehabilitaciones del iusnaturalismo del siglo XX no lo fueron en un sentido estricto. Es significativo que la mayoría de las apuestas que se dieron en esa línea adoptasen una estrategia formalista o procedimental, puesto que con ello renunciaban a la idea de un derecho natural supra-positivo, con contenidos sustanciales cognoscibles y vinculantes. Aquí se encuadra, por ejemplo, el proyecto filosófico de STAMMLER, que diseñó su teoría sobre la base del armazón epistemológico neokantiano, identificando un conjunto de «formas» jurídicas «universales» que debían presuponerse como «condición de posibilidad» del contenido de los ordenamientos vigentes. Ahora bien, esas formas jurídicas no eran más que eso, categorías conceptuales que, en su opinión, debían existir en cualquier experiencia jurídica imaginable, porque son un a priori de nuestra conciencia: objeto y sujeto de derecho, causa y relación jurídica, supremacía y subordinación, juridicidad y antijuridicidad. De la combinación de estas, a su vez, podía extraerse un catálogo aún más nutrido de conceptos jurídicos fundamentales: obligación, prestación, culpa, deber, daño, prohibición, validez, potestad, etc. (STAMMLER, 1911: 109 y ss.). Se trata de una estrategia que, como ha explicado Angelo FALZEA, se asemeja mucho a la que venían cultivando las teorías generales del derecho de cuño positivista (FALZEA, 1992: 57 y ss.). También en este apartado podría señalarse el caso de Lon L. FULLER que, con base en presupuestos diferentes, trató de resucitar al iusnaturalismo mediante una aproximación formal, es decir, desistiendo de postular un conjunto de contenidos «materiales» de derecho natural. En efecto, lo que FULLER denominó «moral interna del derecho» era el resultado de una serie de características procedimentales del derecho que, grosso 
modo, pueden reconducirse a la noción de seguridad jurídica. Esto hizo que muchos autores - entre ellos HART - percibieran como incorrecto calificar a tales elementos de morales, y que muchos positivistas estén de acuerdo con las tesis de FULLER, una vez que las desprendemos de su aura pretendidamente iusnaturalista (EsCUDERO, 2002). En resumidas cuentas, las recuperaciones del derecho natural en clave formal o procedimental no son más que retornos espurios del iusnaturalismo y se dejan aprehender mucho mejor como manifestaciones del paradigma iuspositivista en sentido amplio (GONZÁLEZ VICÉN, 1979: 134-140).

La segunda apreciación que cabe hacer respecto a la resurrección del derecho natural en el siglo XX se refiere a otras propuestas que sí intentaron transitar por la vía iusnaturalista clásica, es decir, que afirmaron la existencia de valores materiales superiores a los ordenamientos jurídico-positivos, ante los que estos debían quedar subordinados. Se trata, en general, de todos aquellos autores que se aferraron a la existencia del derecho natural después de la Segunda Guerra Mundial, como reacción desesperada ante el horror o a modo de antídoto contra una posible reedición de la barbarie nazi. El caso paradigmático es el del segundo RADBRUCH, que llegó a hablar de un «derecho supralegal» (RADBRUCH, 1946). Pero también aquí se encierran varios equívocos. En primer lugar, se trata de una postura que no tuvo una continuidad significativa en la segunda mitad del siglo XX: pasado el estupor de la inmediata posguerra, las posiciones críticas con el positivismo adoptaron otras formas de impugnación menos rotundas, en el entendido de que afirmar la existencia de valores de derecho natural por encima del derecho positivo era más bien una suerte de fideísmo que una posibilidad científica razonable. Desde este punto de vista, podría afirmarse que las teorías del derecho natural de la edad contemporánea son algo así como «frutos fuera de temporada» (BOBBIO, 1989: 377) o «plantas exóticas» (GONZÁLEZ VICÉN, 1986: 324). En segundo lugar, las teorías del derecho natural de posguerra deben entenderse más como un grito éticopolítico que como un verdadero proyecto iusfilosófico. De lo que se trataba era de rehabilitar la profesión del jurista, que había quedado en entredicho tras la divulgación del ignominioso papel que jueces y abogados habían desempeñado en la administración del Tercer Reich. En ese contexto, el recurso al derecho natural hizo las veces de aparato propagandístico para defender el valor de la ética profesional y redignificar un estamento profundamente desacreditado (FOLJANTY, 2013: 298 y ss.).

La que sí ha tenido un eco perdurable es la última de las impugnaciones externas que me gustaría traer a colación: la ofensiva «postpositivista» orquestada en torno a la crítica que DwORKIN realizó a la teoría de HART. Los términos del debate son sobradamente conocidos y sería improcedente entrar en todos sus pormenores. Pero sí me parece necesario destacar dos aspectos relevantes para la presente argumentación. El primero es que el ataque inaugurado por DWORKIN, más tarde proseguido por ALEXY y toda la oleada (neo) constitucionalista, arrancaba del propio derecho positivo. En efecto, el andamiaje sobre el que se asientan todos ellos depende de la constatación —más bien la postulación- de que el derecho positivo tiene una complejidad mayor de la que suponía HART. Según esta propuesta, existiría un tipo de normas, los principios, caracterizados por una densidad moral superior a la de las reglas, lo cual violentaría la pulcra delimitación entre lo ético y lo jurídico que el positivismo había trazado con tesón. Pero creo que la estrategia principialista resulta problemática como ariete para desarbolar al iuspositivismo en su conjunto. En particular, me parece que la jurispru- 
dencia de conceptos se asemeja mucho a la visión del derecho como integridad que propone DWORKIN, y que la naturaleza ambiguamente ética de los conceptos jurídicos en la doctrina de SAVIGNY es muy similar al carácter moral que hoy se suele adjudicar a los principios (GARCÍA AMADO, 2012). Dicho de otro modo, el enfoque dworkiniano serviría para rechazar el iuspositivismo en la versión desarrollada por HART, pero no necesariamente ha de verse como un ataque al paradigma en su totalidad. Además, resulta revelador que la crítica de DwORKIN partiera de una complejización del concepto de derecho positivo, ya que nos coloca ante un planteamiento presuntamente antipositivista que, no obstante, se eleva sobre uno de los legados más firmes de la corriente criticada: la irrenunciable positividad e historicidad del derecho. Esto me lleva a pensar que, si de veras estamos ante una disolución del positivismo, se trata de una disolución mucho menos tajante de lo que suele afirmarse.

El segundo aspecto al que aludía tiene que ver con la forma en que se está empezando a releer la historia de la filosofía jurídica de los últimos dos siglos. Me refiero a la noción de pragmatismo de Manuel ATIENZA, que él atribuye a autores como Ronald DWORKIN y Robert ALEXY, pero que retrotrae a juristas del siglo XIX o principios del XX como Holmes o JHERING (ATIENZA, 2013: 806 y ss.). Se trata de una reconstrucción del pasado interesante, que busca trazar una línea de continuidad entre los enfoques postpositivistas y algunas personalidades del antiformalismo clásico, pero que suscita muchos inconvenientes. Para empezar, el uso de la etiqueta «pragmatismo» resulta discutible, porque pragmatistas en el sentido de ATIENZA serían casi todos los autores y las escuelas positivistas que se han desplegado desde el siglo XIX hasta la fecha. Incluso la jurisprudencia de conceptos se constituyó con una clara vocación política, que consistía en adaptar el viejo derecho romano a las necesidades de la revolución industrial, pero controlando el proceso de cambio desde las élites académicas, y evitando así la democratización que implicaba entregar la batuta del cambio social a un legislador secundado por la legitimidad parlamentaria. Lo que el primer JHERING denominaba ciencia jurídica «productiva» (JHERING, 2013: 251 y ss.) es una manifestación de ese «pragmatismo» que aspira a una ciencia del derecho destinada a solucionar problemas y no a la mera especulación abstracta. Además, la genealogía propuesta por ATIENZA conduce a una paradoja difícil de sortear: si JHERING y HOLMES son exponentes de una tradición pragmatista que desemboca en el postpositivismo, ¿en qué medida pueden seguir siendo considerados positivistas? ¿Se trataría de postpositivistas avant la lettre? $\mathrm{Y}$ en caso de que no lleguemos a afirmar tanto: ¿qué justifica que hablemos de antiformalismo positivista para referirnos a JHERING o HOLMES, mientras que hablamos de antiformalismo postpositivista para aludir a DwORKIN? Creo que al final nos veríamos forzados a reconocer que esta pretendida superación del positivismo no es sino una vuelta de tuerca más en el zozobrante recorrido de este paradigma. Así lo percibió GonZÁLEZ VicÉn cuando ATIENZA y RUIZ MANERo le preguntaron acerca de DworKIN y la extinción del iuspositivismo (GONZÁLEZ VICÉN, 1986: 322-325).

Hasta aquí se ha hecho un repaso de las múltiples críticas externas que ha recibido el positivismo jurídico desde sus inicios, sugiriendo que sería más sensato percibir tales ataques como evoluciones de una corriente heterogénea, en la que caben alternativas teóricas diversas. Pero las cosas son aún más llamativas, puesto que también se han producido numerosas invectivas desde dentro. El primer episodio que he podido encontrar se encuentra en JHERING, que en 1868 pronunció una conferencia en la 
que caracterizó al positivismo como «enemigo mortal de la ciencia jurídica» (JHERING, 1998: 55). En realidad, el jurista alemán estaba pensando en la variante legalista y en el logicismo exacerbado de la jurisprudencia de conceptos. Pero resulta curioso que un autor hoy percibido como arquetipo del positivismo se expresase en esos términos tan contundentes. Más sorprendente aún es el hecho de que, medio siglo más tarde, otro de los representantes típicos del paradigma, KELSEN, se refiriese a JHERING como un remedo enmascarado del iusnaturalismo. En opinión de austriaco, su colega alemán había incurrido en la tentación de incluir un elemento material en su teoría del derecho subjetivo: la idea del interés jurídicamente protegido era para KELSEN un vestigio del derecho natural porque, al tratar de dar una definición de los derechos subjetivos, JHERING no se contentó con señalar sus características formales, sino que introdujo un contenido sustancial, el interés, que inmediatamente reenviaba el problema a consideraciones morales (KELSEN, 1984: 567-618). Las cosas pueden seguir complicándose, porque el mismo KELSEN fue después censurado por Ross por haber erigido una teoría que únicamente podía considerarse «cuasi-positivista» (Ross, 1994: 375 y ss.), una opinión derivada del enfoque naturalista del realismo, según el cual solo una metodología empirista podía ostentar el apelativo de positivista. El último ejemplo de esta batalla interna lo encontramos en la polémica que hoy enfrenta al positivismo incluyente con el excluyente. Al igual que en los casos anteriores, los positivistas excluyentes censuran a sus colegas incluyentes por no ser suficientemente positivistas o, incluso, por tropezar de nuevo en las redes del iusnaturalismo.

Si los ejemplos que he esgrimido hasta ahora son adecuados, me parece evidente que no cabe hablar de la crisis del positivismo como un proceso reciente. Al contrario, podemos afirmar que el paradigma lleva en crisis dos siglos. Son muchos los embates recibidos por parte de oponentes que en su momento pretendieron superar los planteamientos positivistas, y son muchas las diatribas internas que, desde dentro del paradigma, se produjeron en aras de una concepción más «pura» o «auténtica» del positivismo. Teniendo en cuenta todo esto, creo que sería más prudente hablar de una evolución permanente de la concepción positivista, que ha ido adaptándose a los desafíos de cada momento histórico, y que ha ido perfilándose en versiones aparentemente enfrentadas, pero enraizadas en un mismo suelo y dependientes de unos mismos presupuestos. La clave, entonces, estaría en discriminar cuál es ese suelo y cuáles son los cambios históricos que han movido al positivismo a evolucionar en uno u otro sentido. Para responder a esta pregunta, me temo que la única salida es adoptar una perspectiva ideológica, parcialmente coincidente con la de SCARPELLI, y comprender el positivismo como un paradigma que ha ido forjándose como reflejo de las transformaciones del Estado en la Edad contemporánea. Desarrollaré esta idea en el siguiente epígrafe.

\section{LA TRASTIENDA DEL POSITIVISMO JURÍDICO. UN ANÁLISIS IDEOLÓGICO DE LA EVOLUCIÓN DEL PARADIGMA}

Hasta ahora he procedido de la siguiente forma: en primer lugar se rechazó la aproximación conceptual al positivismo, dado que ninguna de las propuestas al uso servía para aprehender en toda su complejidad las múltiples variantes del paradigma; en segundo lugar se procedió a un acercamiento historicista, con el ánimo de incluir en 
una misma horma al positivismo decimonónico y al contemporáneo. El problema de la aproximación conceptual es que circunscribe con tanta precisión el ámbito de lo que debe considerarse positivista, que muchas teorías tradicionalmente concebidas como tales se quedan fuera del mapa. El problema de la aproximación historicista es que, salvada la dificultad anterior, ofrece una visión poco informativa: positivista es toda teoría que entiende el derecho como un producto humano, firmemente enraizado en la historia y dependiente de esta.

La pregunta ahora es: ¿más allá de esta débil afinidad epistemológica, que nos reenvía al hecho sociocultural de la secularización, existe algún rasgo que nos permita identificar el núcleo del positivismo, y que a la vez nos suministre alguna información relevante para comprender su evolución? Aquí es donde se ubica la aportación de SCARPELLI, que me sigue pareciendo la más certera para abordar este problema. De acuerdo con el italiano, hay tres tipos de definiciones, las lexicales, las estipulativas y las explicativas (SCARPELLI, 1997: 52-55). Las primeras tratan de abarcar todos los usos del concepto que se dan en el lenguaje; las segundas tratan de cortar el nudo gordiano estableciendo una definición prescriptiva, pese a que ello implique dejar fuera algunos empleos del concepto que se quiere delimitar; las terceras se sitúan en un terreno intermedio, ya que le dan importancia a la base empírica, pero tratan de buscar un núcleo común que proporcione claves explicativas para comprender el fenómeno. Casándose con esta última perspectiva, SCARPELLI propuso abandonar el enfoque puramente epistemológico y adoptar una mirada política para abordar la cuestión del positivismo. La posición de SCARPELLI es compleja y rica en matices, pero aquí solo me quedaré con uno de los elementos de su argumentación, a saber, el que hace depender el positivismo del Estado de derecho.

Antes de continuar, conviene aclarar que utilizo la expresión Estado de derecho en un sentido débil, asimilable a lo que se denomina Rechtstaat en la tradición alemana, es decir, ese periodo de desarrollo del Estado en el que este logró monopolizar la producción del derecho y empezó a utilizarlo como cauce fundamental de la acción política, que quedaba así sometida al yugo jurídico (COSTA, 2002: 111 y ss.). Se trata de un momento en el que el derecho adquirió un puesto de centralidad en la vida colectiva que anteriormente había sido ocupado por otras esferas de regulación como la religión o la costumbre, y que corrió parejo con un auge formidable de la profesión del jurista, reconvertido en peón al servicio del Estado y en agente principal de la política. Este protagonismo de los juristas dio pie a que el francés Édouard LABOULAYE se mostrase irónico respecto al papel que desempeñaban sus colegas en la vida pública: «unos cuantos abogados son la sal de una Asamblea; pero que se componga de ellos en sus tres cuartas partes, francamente, es demasiado» (ORTEGA, 1989:319). Ese mismo puesto de centralidad del derecho es el que aparece descrito en buena parte de la obra de Max WEBER, y que en alguna ocasión definió como proceso de «burocratización universal» (WEBER, 2008: 112). Con ello se refería a un fenómeno generalizado de juridificación y funcionarización, que provocó el derrame del derecho del Estado en todos los intersticios de la vida social. Como se explicitará en las siguientes páginas, el iuspositivismo fue el correlato intelectual de esta transformación estructural de la política contemporánea.

Así visto, el problema del positivismo jurídico, con todas sus variantes, sus críticas, sus evoluciones, etc., adquiere una enorme nitidez. Incluso el surgimiento de la filoso- 
fía del derecho como disciplina, que GONZÁLEZ VICÉN databa a finales del siglo XVIII y principios del XIX (GONZÁLEZ VICÉN, 1979: 207-257) podría interpretarse desde ese enfoque: la filosofía del derecho sería una nueva rama de los estudios jurídicos que se instaló en la Academia y se configuró como una suerte de portavocía de las necesidades del Estado de derecho. Esta vinculación entre filosofía jurídica y iuspositivismo dio lugar a un modo de teorizar sobre el derecho que debía partir del ordenamiento positivo, no de elucubraciones metafísicas o religiosas, ni de planteamientos éticos extrínsecos, y es la que explica la célebre preferencia de BoBBiO por los juristas-filósofos frente a los filósofos-juristas (BOBBIO, 1977: 43-44). Al contrario de lo que probablemente pensaba el intelectual turinés, esta no era una predilección científica o metodológica, sino claramente política.

Lo que ocurre es que no existe un único modelo de Estado de derecho, ni el Estado se ha mantenido incólume desde el siglo XIX hasta la fecha. Por eso, tanto el positivismo como la filosofía del derecho han ido evolucionando de forma significativa a lo largo de los dos últimos siglos, lo cual justifica las polémicas, la logomaquia y las discrepancias internas ya vistas. A continuación trataré de ofrecer una interpretación de los virajes del paradigma en clave ideológica, tomando en consideración las escuelas que ya se mencionaron en el apartado precedente. Pero es necesaria una advertencia preliminar: esta reconstrucción historiográfica no pretende hacer una lectura política del positivismo en un sentido idéntico al de SCARPELLI o de otras teorías contemporáneas como la de Tom CAMPBELl (CAMPBELL, 2002), que han propuesto la idea de un positivismo ético, normativo o prescriptivo con el ánimo de defender las ventajas morales y políticas de adherirse a una concepción positivista. El punto de vista que aquí manejo es externo y, si se quiere, podría caracterizarse como una crítica de la ideología subyacente — casi siempre inconsciente - a las diversas formas que ha ido asumiendo el paradigma con el paso de las décadas.

La primera variante de positivismo que podemos contemplar es la legalista - positivismo súper estricto, en terminología de Walter Отт (Отт, 1992: 39 y ss.) —, que se asocia paradigmáticamente a la escuela de la exégesis francesa, pero que encontramos en muchos otros contextos. En general, se trata de un tipo de positivismo que fue de la mano con el Estado fuerte característico de principios del siglo XIX, es decir, con ese Estado que logró monopolizar plenamente el uso de la fuerza, que se dotó a sí mismo de un denso aparato burocrático y que pretendió ratificar su dominio mediante la teoría de la ley como única fuente de derecho. El ejemplo de la Francia napoleónica es claro, pero hay otros: la transformación de la escuela histórica del derecho, que a partir del segundo JHERING y de WINDSCHEID comenzó a minusvalorar la costumbre y a reivindicar el papel de la legislación, para llegar hasta el ultra-legalismo de Karl Bergbohm (BergBOHM, 1892: 454-456), se explica en el marco de la Alemania bismarckiana. Ahora bien, esta modalidad de positivismo no solo encontró apoyo en el marco de regímenes cesaristas o autoritarios. De hecho, también los movimientos democráticos que, desde mediados del siglo XIX, pugnaban por la universalización del sufragio, apostaron por esta clase de positivismo, mientras que las fuerzas conservadoras se aferraron a posicionamientos antiformalistas. Este último es el caso de Raymond SALEILLES, maestro de François GÉNY y padre intelectual del derecho comparado, que diferenciaba entre derecho y ley con la voluntad de reservar una esfera de influencia a las élites: por mucho que el parlamento haga la ley, son los juristas quienes se ocupan 
de interpretar, recortar, ampliar o reformar esta en función de criterios casi siempre inconfesables (ARAGONESES, 2009: 120 y ss.). Esto explica el éxito histórico del positivismo legalista, que logró concitar el apoyo de fuerzas aparentemente contradictorias — tanto por la izquierda como por la derecha— y que le procuró una vida más larga de lo esperable.

La siguiente modalidad de positivismo que cabe identificar es la escuela histórica del derecho, opuesta en muchos sentidos a la anterior. Sin embargo, desde el punto de vista ideológico existen lazos significativos entre ambas corrientes. Tanto la una como la otra diseñaron teorías fuertes del sistema jurídico, que concebían a este como un orden cerrado y autosuficiente, muy en la línea de las necesidades de un Estado que exigía para sí el monopolio en el control del derecho, y que no podía permitir fisuras e intromisiones. La diferencia más notable entre ambas direcciones estriba en el aparato filosófico subyacente, y que en el caso de la escuela alemana nos remite al romanticismo y al nacionalismo. De acuerdo con tales ideas, el derecho es el precipitado de la historia de los pueblos, se debe a un espíritu o convicción popular del que no puede prescindir, y se convierte así en un elemento cultural inextirpable de la nación, equiparable a otras manifestaciones de esta como la lengua o la literatura. No por casualidad Jakob GRIMM, el famoso recopilador de cuentos de la tradición germánica, fue discípulo aventajado de SAVIGNY. A él se debe, entre otras cosas, la analogía entre derecho y lengua que tanto usaron los miembros de la escuela histórica (WYSs, 1979). Lo que me interesa destacar ahora es que el positivismo historicista se convirtió en una plataforma inestimable como aparato justificativo del Estado-nación, es decir, de esa fórmula jurídico-política que se convirtió en hegemónica desde entonces hasta bien entrado el siglo XX, y que trata de establecer una ligazón orgánica entre el derecho y la identidad del pueblo. Esto hizo que, desde mediados del siglo XIX, SAVIGNY fuera recibido en España por la escuela jurídica catalana, que trató de parapetar su reivindicación del derecho foral tras las ideas de la corriente historicista (FIGUERAS, 1978), o que en el ámbito anglosajón sus ideas fueran acogidas por el abogado escocés John REDDIE, a modo de escudo contra las intromisiones «legislativas» de la corona inglesa (VOGENAUER, 2015). Hace no muchos años, por cierto, las ideas de SAVIGNY volvieron a ser esgrimidas en la península ibérica por José Ignacio LACASTA, en el marco del problema del nacionalismo vasco (LACASTA, 1998: 94-98).

La introducción del elemento historicista-nacionalista en el núcleo del positivismo generó muchísimas controversias desde el primer momento. En la misma época de SAVIGNY se produjo una sonada escisión de la escuela histórica entre los romanistas y los germanistas, pues estos entendían que la auténtica esencia nacional se encontraba en el antiguo derecho germánico, y no en las pandectas justinianeas que se dedicaban a comentar y reinterpretar los discípulos directos de SAVIGNY. Esta división desencadenó, a finales del siglo XIX, la aparición de un subparadigma pluralista dentro del iuspositivismo, que comenzaría a cosechar sus frutos en el contexto del problema de las nacionalidades de principios del siglo Xx. Un pionero de esta orientación fue Otto VON GIERKE — con su concepción de la comunidad como sujeto de derecho—, pero su promotor más destacado sería Eugen EHRLICH, nacido en una de las regiones más multiculturales del imperio austrohúngaro, la Bucovina, y conocedor de las dificultades derivadas de la coexistencia de diversas tradiciones, lenguas, religiones y experiencias jurídicas en un mismo Estado (ROBLEs MORCHÓN, 2002). De esta problemática se 
hicieron conscientes, en general, casi todas las variantes de antiformalismo sociológico de la primera mitad del siglo XX, que tendieron puentes directos entre derecho, sociedad y cultura, y que facilitaron la adaptación del positivismo a un contexto donde empezaba a hacerse visible la complejidad que se escondía bajo la apariencia de uniformidad de los Estados cristalizados a lo largo del siglo XIX. En este sentido, no es casual que uno de los representantes más destacados del realismo jurídico estadounidense, Karl LLEWELLYN, se asociara con el antropólogo Edward E. HOEBEL para confeccionar un libro acerca del derecho tradicional de los indios cheyennes: The Cheyenne Way (LLEWELLYN y HOEBEL, 1941).

Ahora bien, antes de que se produjera esta reorientación del positivismo, se desarrolló una de las variantes más exitosas del paradigma, y en un sentido ideológico muy distinto al anterior. Me refiero a la teoría general del derecho, tal y como esta fue propuesta por John Austin en Inglaterra. El objetivo de la General Jurisprudence fue responder al dilema que se le había presentado a la ciencia jurídica tras el derrumbe del iusnaturalismo: ¿cómo es posible erigir una ciencia en torno a un objeto tan mudable como el derecho? Si no existe un corpus de normas o principios fijos esperando a ser descubiertos y revelados, ¿qué papel le queda a los juristas científicos? Una de las respuestas que se le dio a este interrogante fue la brindada por la sociología y la antropología jurídicas: ante la irreductible heterogeneidad de experiencias jurídicas del globo, la única salida posible es sociologizar la ciencia del derecho, es decir, contentarse con el estudio y la exposición de las culturas jurídicas existentes, esbozando la trabazón que hay entre el derecho formal y la sociedad en la que este se proyecta, y analizando las brechas que se producen entre ambos niveles. También el derecho comparado en la versión de SALEILLES, con una óptica socio-antropológica y no como mera legislación comparada, sirvió como método para reinventar la investigación jurídica. Pero la otra gran respuesta a este dilema fue la teoría general del derecho, que se elevó sobre la base del siguiente supuesto: pese a que los ordenamientos jurídicos del mundo son tremendamente distintos, y pese a que el contenido del derecho cambia de forma irremediable - tanto en el tiempo como en el espacio- debe de baber algún rasgo formal o estructural compartido por cualquier cultura jurídica. A la búsqueda de dichas características formales es a la que se encaminó la teoría general del derecho (GONZÁLEZ VICÉN, 1981: 5-22).

Tomando como prisma la aproximación ideológica que estoy proponiendo aquí, me parece que la teoría general del derecho debería verse como la derivada que asumió el positivismo en el marco del Estado colonial e imperialista característico del siglo XIX, pero todavía activo en nuestros días. En efecto, si echamos un vistazo a los conceptos generales seleccionados por AUSTIN como presuntamente universales, veremos que se trata, en realidad, de nociones propias del derecho occidental: la distinción entre derecho objetivo y subjetivo, entre propiedad y posesión, entre derecho público y privado, entre objeto y sujeto de derecho, etc. (AUSTIN, 1981: 26 y ss.). Esa universalización de una experiencia particular sirvió para consagrar un canon de lo que puede y no puede concebirse como derecho y, por extensión, terminó generando demarcaciones entre culturas superiores e inferiores. Se trata de una tendencia que sigue vigente en la actualidad, aunque evidentemente bajo diferentes ropajes. Es el caso, por ejemplo, de Mauro BARBERIS, que en su Europa del diritto ha propuesto reservar la etiqueta «derecho» para aquellas culturas, como la occidental, que deslindan con claridad el ámbito jurídico del 
político o el religioso (BARBERIS, 2008). Pero es una conclusión que circula implícitamente incluso en aquellos textos legales más sensibles a la problemática del pluralismo jurídico: en las constituciones de Bolivia, Venezuela, Colombia o Ecuador se habla siempre de «usos y costumbres» $\mathrm{O}$ «tradiciones» para referirse al derecho propio de sus pueblos originarios. Solamente en la constitución mexicana se habla en un momento de los «sistemas normativos» de los pueblos indígenas, aunque en el resto del articulado se vuelve a recurrir a la expresión «usos y costumbres» ${ }^{3}$. Esta tendencia constitutivamente eurocéntrica de la teoría general del derecho ha sido denunciada por William TwINING, que desde hace años viene proclamando la necesidad de rebajar las aspiraciones de generalidad de la teoría del derecho, para hacerla más consciente de la heterogeneidad jurídica del mundo, máxime en la época de la globalización (Twining, 2009).

El último caso de evolución política del positivismo que me gustaría traer a colación tiene que ver con las tendencias sociológicas de la primera mitad del siglo Xx, de las que ya se ha hablado antes. Creo que hay buenas razones para interpretar el giro sociologizante del antiformalismo como una respuesta a la cuestión social que ya se puso de manifiesto en los últimos compases del siglo XIX. El propio JHERING, a quien muchas de estas corrientes vieron como pionero o inspirador, desarrolló su obra tardía con el propósito de acompasar a la ciencia jurídica con las necesidades derivadas de la industrialización, en una orientación teórica que él veía paralela al reformismo social emprendido por Bismarck en la década de los ochenta. Evidentemente, este correlato no debe verse de forma mecánica, ya que no existe en todos los autores, ni puede percibirse con la misma intensidad en todas las escuelas, pero creo que sí es útil establecer un paralelismo entre la socialización del derecho de la primera mitad del siglo XX —constitucionalismo social, génesis del derecho laboral, doctrina de la función social de la propiedad, teoría de la responsabilidad objetiva, etc.- y sociologización del pensamiento jurídico. Es significativo, por ejemplo, que varios representantes del realismo jurídico estadounidense desempeñaran cargos en la administración del New Deal diseñado por el presidente Roosevelt (HoRwITZ, 1992), o que las teorías solidaristas de Léon DUGUIT sirvieran como acicate para algunas políticas sociales que después se verían sistemáticamente consagradas en los Estados sociales de posguerra (LOSANO, 2011). En el mismo sentido - aunque esta vez en clave conservadora - estaría el caso de Philipp HECK, padre de la jurisprudencia de intereses, que estableció una ligazón entre su enfoque antiformalista y los requerimientos de la política social del régimen nacionalsocialista (HECK, 1936). En líneas generales, lo que tuvo lugar fue una adaptación del paradigma positivista a una realidad política compleja, en la que el Estado se estaba viendo asediado por nuevos poderes económicos y por las correspondientes reivindicaciones sociales que, ya desde principios del siglo XX, trataron de hacer sombra a la hegemonía que había ostentado durante la centuria anterior. Para ello, fue necesario abandonar las rigideces del formalismo decimonónico y diseñar una teoría más sensible a la problemática social.

Llegados a este punto, podría decirse que el positivismo ha asumido formas muy diversas y que, en líneas generales, hay una continuidad entre sus propuestas episte-

3 Vid. el art. 2 de la Constitución mexicana, el art. 191 de la Constitución ecuatoriana, los arts. 119 y 186 de la Constitución venezolana, el art. 130 de la Constitución colombiana y el art. 374 de la Constitución boliviana. 
mológicas y la evolución del Estado. Huelga decir que en la mayoría de las ocasiones se trata de una continuidad inconsciente, es decir, que no hay ningún proceso intencional subyacente. De ahí la relevancia del concepto de ideología en el sentido de cosmovisión, episteme o imaginario colectivo: el positivismo tiene ideología, desde luego, pero esta es mucho más compleja y entreverada de lo que daba a entender la clasificación de BoвBIO. Las crisis experimentadas desde principios del siglo XIX hasta la fecha se explican, entonces, como evoluciones internas del paradigma, que ha ido respondiendo a las transformaciones ideológicas del Estado en la Edad contemporánea. Por recapitular, podríamos concluir que el positivismo transitó de la variante legalista a la historicista en el contexto del Estado de derecho decimonónico y del desarrollo de los Estados nación. Posteriormente se desplegó la teoría general del derecho en todas sus manifestaciones - aquí me he referido a AUSTIN, pero también podría haber hablado de BIERLING o de MERKEL, entre otros-y el arco ciertamente heterogéneo de las corrientes pluralistas, en ambos casos como formas de adaptación a la realidad del Estado colonial, que a su vez era una derivada del Estado nación. En última instancia, me he referido a las variantes sociológicas del paradigma como un reflejo del Estado social. En el último apartado trataré de analizar someramente la situación actual y propondré una forma alternativa de comprender la presunta crisis del positivismo.

\section{LA CRÍTICA (NEO) CONSTITUCIONALISTA. ¿ESTAMOS HOY ANTE LA CRISIS DEFINITIVA?}

¿En qué situación nos hallamos ahora? Como se deriva de lo dicho hasta aquí, me parece extremadamente difícil hacer diagnósticos acerca del momento presente, y creo que la historia expuesta nos da motivos prudenciales para no incurrir en planteamientos categóricos. De algún modo, me sucede algo parecido a lo que se relata en la fábula del lobo y las ovejas: de tanto anunciar la crisis del positivismo, sin que esta haya llegado de manera definitiva, tiendo a desconfiar de las voces que hoy en día proclaman su superación. Sin embargo, también creo que nos encontramos en un momento de cambio indiscutible, que tiene que ver con las transformaciones copernicanas que la globalización está provocando en nuestra forma de comprender el derecho. No es el momento de entrar en un análisis pormenorizado de todos estos cambios, pero sí me parece necesario destacar que el denominador común de estas mutaciones es la erosión irrevocable de la autoridad del Estado y el surgimiento de un ordenamiento global en el que este ya no es el agente principal de la política. Fenómenos como la denominada lex mercatoria o el soft law - con todo lo ambiguo de estas expresiones (LAPORTA, 2007: 243 y ss.) - , el constitucionalismo multinivel, el estallido y visibilización del pluralismo jurídico o la profunda penetración del campo económico en la esfera política y jurídica son algunas de las manifestaciones de este fenómeno generalizado.

En parte, la filosofía jurídica ha reaccionado a este estado de cosas. En una primera fase, de entre las mismas filas del positivismo surgió la teoría del derecho internacional, con el viejo debate entre el monismo y el dualismo que enfrentó a KELSEN con las doctrinas de TRIEPEL o ANZILOTTI, y que pugnaba por dotar de juridicidad al derecho internacional, algo que había sido cuestionado en el siglo XIX por filósofos positivistas como John Austin (WALZ, 1930). Ahora bien, en una segunda fase, la teoría jurídica 
ha adquirido una consciencia mucho más profunda de la trascendencia de la globalización y, si se me permite el tropo, está transitando de la clásica teoría del derecho internacional a una teoría internacional del derecho. Con esto me refiero a una concepción del derecho que desborda los límites del Estado-nación y que se hace cargo de la irremediable degradación de la soberanía en el mundo contemporáneo, reivindicando una teoría jurídica menos «pura» y más cercana a la sociología, la antropología o el derecho comparado. Aquí podríamos incluir — cada una con sus peculiaridades - a la teoría del droit global de Benoît FRYDMAN (FRYDMAN, 2012), a la Global Jurisprudence de Twining (Twining, 2009), a las consideraciones filosófico-jurídicas del Imperio de HARDT y NEgRI (HARDT y NEGRI, 2005: 21-42) o, entre nosotros, a la teoría comunicacional del derecho de Gregorio RoBLES (ROBLES, 2007). Todas ellas apuestan por un paradigma pluralista — superador del rígido debate entre monismo y dualismo-y comparten la convicción de que la teoría jurídica no puede seguir obcecándose en encajar los conceptos fraguados al amparo del derecho estatal del siglo XIX en un contexto de relaciones globales que desbordan con creces dicho marco. En este sentido, la teoría del derecho debería hacerse cargo de la variedad de experiencias jurídicas que coexisten en el globo y, sobre todo, del mestizaje permanente que se produce entre todas ellas.

Creo que el giro ético promovido en la filosofía a partir de los años setenta del siglo XX, e implícitamente presente en las propuestas teóricas de DwORKIN o ALEXY, forma parte de este conjunto de transformaciones que vivimos, y que podrían interpretarse como un tránsito de la modernidad a la posmodernidad. El tema de la posmodernidad es por sí mismo complejo y genera virulentas adhesiones a favor y en contra. Aclaro desde el primer momento que estoy asumiendo la noción de posmodernidad como un descriptor de las mutaciones generalizadas que se han producido en todos los órdenes del saber a partir de los años setenta y que, en ese sentido, nos afecta a todos, incluso a aquellos que reniegan de ella. Por eso, como propone Boaventura DE SOUSA SANTOS, conviene diferenciar entre un posmodernismo celebratorio - conservadory un posmodernismo de oposición — progresista— (SANTOS, 2009: 29 y ss.). Se trata de un proceso cultural que no cabe explicar aquí con toda la exhaustividad deseable, pero que, en general, ha implicado una crisis radical de la noción de sujeto, tal y como esta se había forjado al calor de la modernidad. Hay que tener en cuenta que la teoría del sujeto fue uno de los ámbitos de reflexión filosófica más complejos y a la vez más representativos de la Edad moderna: desde el cogito ergo sum cartesiano, pasando por las doctrinas del self del empirismo anglosajón, hasta la idea de la alienación marxista, el mundo moderno elevó todos sus proyectos filosóficos sobre dicha noción, a veces de forma expresa y a veces de forma implícita. En efecto, por muy problematizada que estuviera, la idea de un sujeto estable es la piedra angular que explica el surgimiento de la biografía como género literario, el a priori de la conciencia en la epistemología kantiana, el método del psicoanálisis freudiano y hasta el solipsismo del primer WITTGENSTEIN, entre muchísimos otros ejemplos que podrían argüirse.

Es verdad que el concepto fue mutando en función de las épocas y las escuelas, pero en cualquiera de sus variantes se mantuvo una idea relativamente fija del sujeto (BRONCANO, 2013), como un pilar incuestionable sobre el que levantar cualquier entramado de proposiciones teóricas o de proyectos prácticos imaginables. Esta suerte de pacto metafísico tácito se plasmó políticamente en las teorías del pacto social y en el 
nacimiento correlativo de una mentalidad individualista que, a su vez, se transfirió al ámbito jurídico mediante la doctrina de los derechos subjetivos. Lo que me interesa destacar ahora es que el trasunto de esta lógica del sujeto en el plano colectivo fue la teoría de la soberanía, o sea, la concepción de un sujeto político autónomo e investido de autoridad que no reconoce superior. Es significativo que tanto la noción de autonomía como la de autoridad - ambas marcadas por el prefijo auto- sean definitorias de la soberanía, porque reenvían la cuestión a la idea del sí mismo, de la identidad. En definitiva, el problema de la soberanía no es sino el problema del sujeto en la órbita política y social. Tanto las teorías mecanicistas, características del siglo XVIII, como las doctrinas organicistas del siglo XIX, coinciden en una percepción del Estado como sujeto soberano: en el primer caso el Estado es un artefacto cultural que engrana las subjetividades individuales en una maquinaria política superior —el Estado como persona jurídica - mientras que en el segundo caso el Estado es un organismo natural que hipostasia las subjetividades individuales en un cuerpo político totalizador (STOLLEIS, 1992: 123-125). En ambos casos, no obstante, subyace la metafísica moderna del sujeto.

Esta equivalencia entre la doctrina del sujeto y la doctrina de la soberanía ya fue vista con acierto por Léon DUGUIT en su clásico Las transformaciones del derecho público de 1913, cuando apostó por abandonar ambas ideas como ejes del derecho público contemporáneo: a su modo de ver, se trataba de nociones obsoletas en el marco de los Estados industrializados, que deberían ser reemplazadas por el concepto de servicio público (Duguit, 1913: IX-XIX). Pese a que Duguit no llegó a conocer el brutal desgaste de la soberanía en el contexto de la globalización, es significativo que ya a principios del siglo XX se hiciera una observación semejante. Y es particularmente interesante para la presente argumentación, porque pone de relieve que ya en aquel entonces había comenzado a deteriorarse la soberanía tal y como esta fue definida en la época moderna. De hecho, como ha observado Ugo MATTEI, «la teoría y la praxis de la soberanía solo coincidieron en algunas raras hipótesis - geográficamente delimitadas - en las que un aparato estatal moderno fue capaz de dotarse de una burocracia, de una policía y de un sistema capilar de tribunales de justicia. Esto ocurrió en Europa solo en casos relativamente excepcionales y tardíos, como la Francia napoleónica, la Alemania bismarckiana o la Inglaterra victoriana» (MATTEI, 2013: 30). Desde esta perspectiva, la evolución del iuspositivismo analizada en los acápites anteriores podría verse como un intento desesperado por rezurcir la teoría a una realidad que poco a poco iba revelando la imposibilidad de mantener incólume el sueño estatal de la modernidad. La apreciación visionaria de DuguiT no fue sino uno de esos episodios de rehabilitación, que en su caso se enmarca bajo la rúbrica del positivismo sociológico.

Con todo, es solo en la posmodernidad cuando este proceso ha llegado a umbrales verdaderamente palpables y las concepciones tradicionales han estallado por los aires. La reflexión filosófica se ha dedicado a tematizar la crisis del sujeto a través de múltiples estrategias, que a menudo se han centrado en observar la aparición de identidades fragmentarias, móviles, fluidas, o bien en el rechazo de las dicotomías que habían servido para apuntalar la noción fija del sujeto en la modernidad: naturaleza y cultura, hombre y mujer, alma y cuerpo, razón y sentimiento, etc. La filósofa feminista Donna HARAWAY ha utilizado la metáfora del ciborg para referirse a este fenómeno de hibridación entre cultura y naturaleza, entre animalidad y tecnología que caracteriza a 
lo humano, y que nos lleva a vivir siempre en la frontera, borrando límites y trazando nuevas lindes provisionales (HARAWAY, 1995: 251 y ss.). Ahora bien, también en el mundo del derecho existen ciborgs, especies jurídicas híbridas surgidas al calor de la globalización, que no encajan en los moldes de la teoría decimonónica. Esto explica el resquebrajamiento de la noción de sujeto de derecho, que poco a poco ha ido asumiendo formas aberrantes para la cosmovisión moderna: desde la idea de derechos colectivos hasta la reciente atribución de personalidad jurídica a un río —esto ha sucedido en algunas comunidades maoríes de Nueva Zelanda-, pasando por la extraña locución de «derechos de la pacha-mama», el sujeto de derecho de la modernidad parece haber entrado en un frenesí de metamorfosis permanente (MíGUEZ, 2014). Este tipo de fenómenos de transfiguración, típicamente posmodernos, se vienen dando desde hace décadas y se proyectan en multitud de ámbitos. En particular, es notorio el cruce de culturas jurídicas que se está produciendo como consecuencia de la globalización, y que han llevado a Benoît FRYDMAN a utilizar el concepto de OJNIS (Objetos Jurídicos No Identificados) para describir esa clase de instituciones extrañas para las concepciones tradicionales (FrYDMAN, 2012: 20 y ss.).

Al igual que el sujeto de derecho, la noción de soberanía se ha problematizado desde hace décadas y existe la percepción generalizada de que el mundo ha entrado en una fase post-estatal que está dando lugar a un nuevo statu quo global. Sin embargo, la incertidumbre es poderosa y hay una inercia difícil de resistir, que tiende a seguir interpretando el derecho a la luz de las categorías tradicionales. No es el momento de entrar en todas las derivadas que se desprenden de este fenómeno, pero sí me gustaría subrayar la concomitancia entre la posmodernidad como hecho cultural y el desmantelamiento de la soberanía como hecho político. Como han mostrado HARDT y NEGRI en Imperio, no se trata de un paralelismo casual, sino que son dos caras de la misma moneda, dos facetas de un proceso que nos está conduciendo a un nuevo orden imperial en el que ya no existe una única potencia hegemónica, en el que los poderes son múltiples, lábiles y fragmentarios, y donde el dominio no se ejerce de manera vertical, sino reticular. Es imposible abordar todo esto en esta sede, pero sí me interesaría ligar esta dinámica con la idea de deconstrucción, que no por casualidad es uno de los emblemas de la posmodernidad. Interpretándola en clave de la presente argumentación, podría decirse que el derecho ha sufrido un proceso de deconstrucción en diferentes ámbitos: la descodificación y la correlativa proliferación de legislación especial (IRTI, 1992), la aparición de normas difícilmente clasificables, cuyos efectos oscilan entre lo político y lo jurídico — pensemos en las recomendaciones del derecho internacional-, un constitucionalismo que ha dinamitado la visión piramidal del ordenamiento para adoptar constituciones de múltiples vértices (TROPER, 2001) o el auge de formas alternativas de resolución de conflictos como la mediación o la conciliación (AGUILÓ, 2015) son solo algunas de las manifestaciones de esta transformación global.

Pero conviene hacer una advertencia: la clave de este recorrido deconstructivo no es la «fragmentación», la «descomposición» en partes o la «desestructuración» del derecho. Todos esos pueden ser síntomas o etapas de un proceso general más profundo e incisivo, que podría describirse mejor con las etiquetas de «difuminación», «disolución» o «conmixtión» del derecho con otras esferas. Si se me permite una analogía, algo parecido sucede con las artes plásticas: la esencia de la deconstrucción en pintura no se encuentra en el largo itinerario de descomposición de las formas que condujo desde 
el impresionismo hasta el suprematismo abstracto de MALÉviCH, sino en el fenómeno por el cual la pintura perdió la vanguardia de los movimientos artísticos y le cedió el testigo a la performance, o en el hecho de salir de los museos e instalarse en las calles a través del grafiti, o en el proceso por el cual se hibridó con la literatura dando lugar al cómic. Todos estos son fenómenos típicamente posmodernos que ya se produjeron hace varias décadas y que no tienen que ver con la descomposición de las formas pictóricas, sino más bien con la misma «disolución» de la pintura y de su papel en el mundo de las artes. Creo que la deconstrucción del derecho debe interpretarse en esa clave y que, por tanto, la posmodernidad jurídica consiste en el fenómeno de disolución y desaparición del derecho. Por utilizar una expresión que ya se empleó antes, en su pérdida de centralidad. En este sentido, me parece que las tesis marxistas que defendieron la superación del derecho y el Estado han adquirido una actualidad inesperada en el contexto de la globalización, solo que no como se pensó en su momento: no es que el derecho deba desaparecer, sino que el derecho está desapareciendo de facto. Obviamente, esto no quiere decir que desaparezcan las normas y la regulación. Al contrario, los poderes que nos gobiernan, el control biopolítico al que estamos sometidos y los focos de producción de normas globales parecen ser cada vez más opresivos y numerosos (HARDT y NEGRI, 2005). Pero estos poderes ya no son los del Estado, ni sus agentes principales son los juristas, sino una pléyade de instituciones, entidades y profesionales de índole económica, financiera o política que, eventualmente, utilizan el derecho, pero que han reemplazado a los juristas en el puesto de primacía que tuvieron en la modernidad.

Este proceso de disolución ha sufrido varias fases y consiste, esencialmente, en el desvanecimiento de los límites del derecho, que está perdiendo el estatus de aislamiento o autonomía con el que se había revestido a lo largo de la historia moderna (RÜCKERT, 1988) y que está dando lugar a una confusa amalgama de la esfera jurídica con la moral, la economía o la política. Aquí es donde entra el giro ético de la filosofía posmoderna y, en lo que nos afecta, el giro argumentativo de la filosofía jurídica contemporánea. La conceptualización del derecho como una ramificación más de la razón práctica y su correlativa equiparación con la ética o la política, la transfiguración de la teoría de la ciencia jurídica en las teorías de la argumentación (GARCÍA AMADO, 1986), el reemplazo de la racionalidad por la razonabilidad o muchos otros rasgos del paradigma postpositivista son ideas característicamente posmodernas, que apuntan hacia la disolución de las barreras del derecho como un ámbito profesional y científico aislado. Además, si prestamos atención, todos los ejemplos que acabo de citar nos reenvían a una concepción del derecho como discurso, algo en lo que las teorías postpositivistas coinciden, paradójicamente, con un arquetipo de la filosofía posmoderna como Richard RORTY, cuando este nos proponía abandonar el paradigma de la fundamentación racional de los derechos, para sustituirlo por el de la narración «de historias tristes y sensibles» (RORTY, 1998).

Ahora bien, lo relevante es la concomitancia de todas estas transformaciones con la era de la post-soberanía. Nótese que la crítica principialista de DwORKIN tiene lugar en los años setenta, es decir, en un momento en el que se empiezan a poner en cuestión las políticas sociales de los Estados del bienestar, coincidiendo prácticamente con la publicación de Law, Legislation and Liberty de Friedrich HAYEK o con la Teoría de la justicia de John RAWLS, y con el florecimiento de la crítica al paternalismo estatal, una tendencia académica que no cabe interpretar como algo puramente azaroso. Creo que 
la apelación a la moral de la oleada neoconstitucionalista, que también nos encontramos en el auge de las deontologías profesionales o en la retórica de las virtudes promovida por cierta clase de republicanismo moralizante, debe interpretarse como un síntoma de la crisis del Estado, como una suerte de refugio en la ética ante el desplome de las instituciones tradicionales. Y es que, como pensaba María ZAMBRANO, la moral florece en tiempos de crisis, mientras que la política lo hace en tiempos de esplendor (ZAMBRANO, 1992: 21 y ss.). Obviamente, todas estas derivas no están conectadas entre sí de forma causal, directa e intencional, sino que constituyen una trama compleja cuyas costuras se han ido trenzando de manera silenciosa e inconsciente, pero cuyo dibujo puede hoy apreciarse con algo de nitidez.

Así las cosas, no creo que el embate neoconstitucionalista signifique por sí mismo una demolición del paradigma positivista, pero sí me parece que debe ser interpretado como otra de las crisis que ha vivido esta corriente. Lo particular de esta crisis es que quizá sea más severa que las anteriores, porque afecta a los mismos cimientos del Estado. Hoy, más de treinta años después de que DwORKIN pusiera sus cartas sobre la mesa, el desmantelamiento de las estructuras estatales —o más bien la disipación de las fronteras entre la esfera del Estado y la del mercado mundial— está tremendamente avanzado. Si hacemos caso de la argumentación precedente y suscribimos la tesis de que el positivismo jurídico nació y evolucionó conforme a las derivas que el Estado experimentó en los dos últimos siglos, entonces quizá sí quepa diagnosticar la existencia de una crisis paradigmática desconocida hasta ahora. Lo que ocurre es que esta crisis no tendría que ver con la desaparición de los lindes entre el derecho y la moral, como parece decírsenos desde las filas neoconstitucionalistas, sino con un cambio trascendental en la esfera global, que se explica mejor a través de la tensión entre derecho y política o entre derecho y economía, y en el marco de las teorías internacionales del derecho. Este cambio está dando lugar a lo que antes caractericé como pérdida de centralidad del derecho, en la medida en que la regulación de la vida se encomienda a otras esferas, fundamentalmente económicas. A veces, esto se manifiesta de manera indirecta, cuando el derecho público asume el discurso de la economía global y adopta las formas del derecho corporativo o comercial —la «huida» del derecho administrativo- o cuando el ejercicio de la abogacía se pliega a los usos y la estética empresarial.

En paralelo a este proceso, que por sí mismo no tiene nada de halagüeño —más bien lo contrario - se está produciendo, no obstante, un reverdecer de la política. De hecho, pese a que se escucha a menudo el lema de la «juridificación de la política», creo que lo que se está produciendo es el fenómeno inverso: una profunda politización del derecho. Desde este punto de vista, me parece que la tensión fundamental a la que debería prestar atención la teoría jurídica no es la de derecho y moral, sino la de derecho y política. De hecho, ya hay signos reveladores en esta línea: la aparición del denominado constitucionalismo popular estadounidense (NIEMBRO, 2013), del llamado nuevo constitucionalismo latinoamericano (VICIANO y MARTínEZ DALMAU, 2012: 11-49) o de la justicia dialógica (GARGARELLA, 2014), con todas sus diferencias, son manifestaciones de una cultura que pretende aminorar la brecha entre la esfera del derecho - fuertemente tecnificado- y la ciudadanía, haciendo hincapié en la dimensión participativa que ha de asumir el derecho de nuestros días. Todas estas corrientes, en efecto, pugnan por re-politizar la Constitución o el ámbito jurisdiccional en general, en el entendido de que también el derecho y su práctica deben ser objeto de deliberación 
democrática. Evidentemente, todas estas expresiones pueden interpretarse desde la base del positivismo en su versión mínima - positivismo metodológico, tesis de las fuentes sociales, convencionalismo-, pero eso no quiere decir que el paradigma siga vivo. Las teorías pueden fracasar por dos razones: o bien porque no logran abarcar semánticamente el fenómeno o el conjunto de fenómenos que se proponen describir, o bien porque dejan de plantear las preguntas relevantes. Tengo la impresión de que, si esta vez el positivismo ha fracasado, lo habrá hecho por esta segunda razón.

\section{BIBLIOGRAFÍA}

Aguiló, J., 2015: El arte de la mediación: argumentación, negociación y mediación, Madrid: Trotta.

ARAgOneSES, A., 2009: Un jurista del modernismo. Raymond Saleilles y los orígenes del derecho comparado, Madrid: Dykinson.

ATIENZA, M., 2013: Curso de argumentación jurídica, Madrid: Trotta.

AtienZA, M., y Ruiz MANERo, J., 2007: «Dejemos atrás el positivismo jurídico», Isonomía, 27: $7-28$.

ATRIA, F., 2004: «La ironía del positivismo jurídico», Doxa, 27: 81-139.

Austin, J., 1981: Sobre la utilidad del estudio de la jurisprudencia, F. GONZÁlez VicÉN (trad. y estudio preliminar), Madrid: Centro de Estudios Políticos y Constitucionales.

BARBERIS, M., 2008: Europa del diritto, Bologna: Il Mulino.

BAYÓN, J. C., 2002: «El contenido mínimo del positivismo jurídico», en V. ZAPATERO, Horizontes de la filosofía del derecho. Homenaje a Luis García San Miguel, Alcalá de Henares: Servicio de Publicaciones de la Universidad de Alcalá, 33-54.

Bergbohm, C., 1892: Jurisprudenz und Rechtsphilosophie. Kritische Abhandlungen, vol. 1, Lepzig: Duncker \& Humblot.

BobBIO, N., 1977: Giusnaturalismo e positivismo giuridico, Milano: Edizioni di Comunità.

- 1989: «Hegel y el iusnaturalismo», en G. AmENGUAL (ed.), Estudios sobre la Filosofía del Derecho de Hegel, Madrid: Centro de Estudios Constitucionales, 377-406.

- 1996: Il positivismo giuridico. Lezioni di filosofia del diritto raccolte dal dott. Nello Morra, Torino: Giapichelli.

- 2005: Teoría general del derecho, 2. ${ }^{a}$ ed., J. GuERRERO (trad.), Bogotá: Temis.

BRONCANO, F., 2013: Sujetos en la niebla. Narrativas sobre la identidad, Barcelona: Herder.

CAMPBELl, T., 2002: «El sentido del positivismo jurídico», Doxa, 25, 303-331.

CARRIÓ, G., 1981: Dworkin y el positivismo jurídico, México: UNAM.

Contreras Peláez, F., 2005: Savigny y el historicismo jurídico, en A. E. Pérez LuÑo (pról.), Madrid: Tecnos.

COSTA, P., 2002: «Lo Stato di diritto: un'introduzione storica», en P. CosTA y D. ZOLO (eds.), Lo Stato di diritto. Storia, teoria, critica, Milano: Feltrinelli, 89-170.

DrEIER, H., 2007: «Naturrecht und Rechtspositivismus. Pauschalurteile, Vorurteile, Fehlurteile», en W. Härle y B. Vogel, Vom Rechte, das mit uns geboren ist. Aktuelle Probleme des Naturrechts, Freiburg: Herder, 127-169.

DREIER, R., 1993: «Jherings Rechtstheorie - eine Theorie evolutionärer Rechtsvernunft», en O. BeHRENDS, Privatrecht heute und Jherings evolutionäres Rechtsdenken, Köln: Dr. Otto Schmidt, 111-129.

Duguit, L., 1913: Les transformations du droit public, Paris: Librairie Armand Colin. 
Escudero Alday, R., 2002: «Argumentos para la recuperación de la teoría de Lon L. Fuller», Anuario de Filosofía del Derecho, XIX, 309-331.

- 2004: Los calificativos del positivismo jurídico. El debate sobre la incorporación de la moral, Madrid: Thomson-Civitas.

Falk, R. A., y Shuman, S. I., 1961-1962: «The Bellagio Conference on Legal Positivism», Journal of Legal Education, 14, 213-228.

FALZEA, A., 1992: Introduzione alle scienze giuridiche (I). Il concetto del diritto, Milano: Giuffré.

FAssò, G., 2006: Storia della filosofia del diritto, vol. III. Ottocento e Novecento, 9. ${ }^{a}$ ed. aggiornata, C. FARAlli (a cura di), Roma-Bari: Laterza.

Ferrajoli, L., 2011: Principia Iuris. Teoría del derecho y de la democracia (vol. 1), en P. Andrés, J. C. Bayón, M. Gascón, L. Prieto y A. Ruiz Miguel (trads.), Madrid: Trotta.

Figueras, M., 1978-1979: «Notas sobre la introducción de la Escuela Histórica de Savigny en España», Anales de la Cátedra Francisco Suárez, 18-19, 371-393.

FolJANTY, L., 2013: Recht oder Gesetz: Juristische Identität und Autorität in den Naturrechtsdebatten der Nachkriegszeit, Tübingen: Mohr Siebeck.

Frydman, B., 2012: «Comment penser le droit global?», en J.-Y. CHÉROT y B. FrYdMAN (dirs.), La science du droit dans la globalisation, Bruxelles: Bruylant, 17-48.

GARCía Amado, J. A., 1986: «Del método jurídico a las teorías de la argumentación», Anuario de Filosofía del Derecho, 3, 151-182.

- 2012: «Sobre formalismos y antiformalismos en la teoría del derecho», Eunomía. Revista en cultura de la legalidad, 3, 13-43.

Gargarella, R. (ed.), 2014: Por una justicia dialógica. El Poder Judicial como promotor de la deliberación democrática, Buenos Aires: Siglo XXI.

GIERKE, O. VON, 1883: Naturrecht und Deutsches Recht. Rede zum Antritt des Rektorats der Universität Breslau, Frankfurt am Main: Literarische Anstalt Rutten \& Loening.

GonZÁlez VicÉn, F., 1979: Estudios de filosofía del derecho, Santa Cruz de Tenerife: Universidad de La Laguna.

- 1981: «Estudio preliminar», en J. Austin, Sobre la utilidad del estudio de la jurisprudencia, Madrid: Centro de Estudios Políticos y Constitucionales, 5-22.

- 1984: «Del Derecho natural al positivismo jurídico», De Kant a Marx (Estudios de historia de las ideas), Valencia: Fernando Torres, 206-221.

- 1986: «Entrevista con Felipe González Vicén», en M. AtienZa y J. Ruiz Manero (eds.), Doxa, 3, 317-325.

HARAWAY, D., 1995: Ciencia, cyborgs y mujeres. La reinvención de la naturaleza, en M. TALENS (trad.), Madrid: Cátedra.

Hardt, M., y Negri, A., 2005: Imperio, en A. Brixio (trad.), Barcelona: Paidós.

Hart, H. L. A., 1958: «Positivism and the Separation of Law and Morals», Harvard Law Review, 71 (4), 593-629.

- 1990: «El nuevo desafío del positivismo jurídico», en F. LAPORTA, L. Hierro y J. R. DE PÁRAMO (trads.), Sistema, 36, 3-19.

HecK, P., 1936: Rechtserneuerung und juristische Methodenlebre, Tübingen: J. C. B. Mohr.

HiERro, L., 2008: El realismo jurídico escandinavo. Una teoría empirista del derecho, 2. ed., Madrid: Iustel.

Hoerster, N., 2000: En defensa del positivismo jurídico, J. MALEm (trad.), 2. ${ }^{\text {a }}$ ed., Barcelona: Gedisa.

HoRwITZ, M. J., 1992: The Transformation of American Law, 1870-1960: The Crisis of Legal Orthodoxy, Oxford: Oxford University Press. 
IRTI, N., 1992: La edad de la descodificación, en L. ROJO AJURIA (trad.), Barcelona: Bosch.

JHERING, R. VON, 1998: Ist die Jurisprudenz eine Wissenschaft? Jherings Wiener Antrittsvorlesung vom 16. Oktober 1868, en O. BEHRENDS (Hrsg.), Göttingen: Wallstein.

- 2013: «Nuestra tarea», en L. LLOREDO ALIX (trad. y estudio preliminar), Eunomía. Revista en cultura de la legalidad, 4, 234-275.

Kantorowicz, H., 1906: Die Kampf um die Rechtswissenschaft, Heidelberg: Carl Winter's.

KELSEN, H., 1984: Hauptprobleme der Staatsrechtslebre (Entwickelt aus der Lebre vom Rechtssatze), 2. ${ }^{a}$ ed., Darmstadt: Scientia.

LACASTA, J. A., 1998: «Savigny eta Iheringen artean (ez duzu Savignyren izena ahotan alferrik hartuko», Euskal Herriko legelarien aldizkaria, 3, 94-98.

LAPORTA, F., 2007: El imperio de la ley. Una visión actual, Madrid: Trotta.

LENK, K., 2000: «Las etapas esenciales en la concepción de la ideología», en K. LENK, El concepto de ideología. Comentario crítico y selección sistemática de textos, 2. ${ }^{a}$ ed., J. L. ETCHEVERRY (trad.), Buenos Aires: Amorrortu, 9-46.

Llewellyn, K., y Hoebel, E. A., 1941: The Cheyenne Way: Conflict and Case Law in Primitive Jurisprudence, Oklahoma: University of Oklahoma Press.

LlOREDO Alix, L., 2014: «La recepción de Savigny en España. Un episodio en la historia de la circulación de las ideas», Derechos y Libertades, 30, 227-268.

- 2015: «Una propuesta de redefinición de la teoría jurídica a la luz del movimiento de los indignados», en J. A. GARCía SÁEZ y R. VAÑó (eds.), Educar la mirada. Documentales para una enseñanza crítica de los derechos bumanos, Valencia: Tirant lo Blanch, 209-227.

LosAno, M. G., 2002: Sistema e struttura del diritto (I): Dalle origini alla Scuola storica, Milano: Giuffré.

— 2011: «Las teorías del solidarismo y su influencia en la formulación de los derechos fundamentales económicos», en M. G. LosAno (ed.), Solidaridad y derechos bumanos en tiempos de crisis, C. LEMA y L. LlOREDO (trad.), Madrid: Dykinson.

MENZEL, A., 1922: Kallikles. Eine Studie zur Geschichte der Lebre vom Rechte des Stärkeren, Wien/Leipzig: Franz Deuticke.

Míguez, R., 2014: «De las cosas comunes a todos los hombres. Notas para un debate», Revista Chilena de Derecho, 41 (1), 7-36.

Murphy, M. C., 1995: «Was Hobbes a Legal Positivist?», Ethics, 105, 846-873.

Niembro, R., 2013: «Una mirada al constitucionalismo popular», Isonomía, 38, 191-224.

NiNO, C. S., 2003: Introducción al análisis del derecho, 2. ${ }^{a}$ ed. ampliada y revisada, Buenos Aires: Astrea.

OliveCrOnA, K., 2013: «Realismo e idealismo. Algunas reflexiones sobre la cuestión capital de la filosofía del derecho», en O. VERGARA (trad. y ed.), Eunomía. Revista en cultura de la legalidad, 5, 248-263.

Ortega y Gasset, J., 1989: «España», en P. GARRAgOrRi (ed.), Obras completas. Vol. X (Ideas políticas), Madrid: Alianza.

OTT, W., 1992: Der Rechtspositivismus. Kritische Würdigung auf der Grundlage eines juristischen Pragmatismus, 2. ${ }^{a}$ ed., Berlin: Duncker \& Humblot.

PAŠUKANIS, E., 1976: Marxismo y teoría general del derecho, en V. ZAPATERO (trad. y presentación), Barcelona: Ediciones Labor.

Pérez Lledó, J. A., 1996: El movimiento Critical Legal Studies, Madrid: Tecnos.

RADBRUCH, G., 1946: «Gesetzliches Unrecht und übergesetzliches Recht», Süddeutschen Juristen-Zeitung, 5 (August), 105-108.

- 1960: Die Natur der Sache als juristische Denkform, Darmstadt: Wissenschaftliche Buchgesellschaft. 
RIVAYA, B., 2009: «Historia política de la filosofía del derecho española del siglo XX», Doxa, 32 : 541-582.

Robles Morchón, G., 2002: Ley y derecho vivo. Método jurídico y sociología del derecho en Eugen Ehrlich, Madrid: Centro de Estudios Políticos y Constitucionales.

RORTY, R., 1998: «Derechos humanos, racionalidad y sentimentalidad», en S. SHUTE y S. HuRLEY (eds.), De los derechos humanos. Las conferencias Oxford Amnesty de 1993, Madrid: Trotta, 117-136.

Ross, A., 1994: «El concepto de validez y el conflicto entre el positivismo jurídico y el derecho natural», en P. CASANOvaS y J. J. MORESO (eds.), El ámbito de lo jurídico. Lecturas de pensamiento jurídico contemporáneo, Barcelona: Crítica, 361-382.

RÜCKERT, J., 1988: Autonomie des Rechts in rechts historischer Perspektive, Hannover: Juristische Studiengesellschaft.

- 2011: «Freirechtsbewegung», en Handwörterbuch zur deutschen Rechtsgeschichte, Berlin: Erich Schmidt Verlag.

SAnTOS, B. DE, 2009: Sociología jurídica crítica. Para un nuevo sentido común en el derecho, en C. LEMA (nota introductoria y revisión de la trad.), Madrid: Trotta.

SAVIGnY, F. K. VON, 1814: Vom Beruf unsrer Zeit für Gesetzgebung und Rechtswissenschaft, Heidelberg, Mohr und Zimmer.

- 1993: Vorlesungen über juristische Methodologie 1802-1842, A. MAZZACANE (Hrsg.), Frankfurt am Main: Vittorio Klostermann.

SCARPELli, U., 1997: Cos'è il positivismo giuridico, en A. CATANIA y M. Jori (introduzione e cura), Napoli: Edizioni Scientifiche Italiane.

STAMmLER, R., 1911: Theorie der Rechtswissenschaft, Halle: Waisenhaus.

STOLLeIS, M., 1992: Geschichte des öffentlichen Rechts in Deutschland, II. Band (1800-1914), München: C. H. Beck.

Troper, M., 2001: Por una teoría jurídica del Estado, en M. Venegas (trad.), G. PeCes-BArbA (pról.), Madrid: Dykinson.

TwinING, W., 2009: General Jurisprudence. Understanding Law from a Global Perspective, Cambridge: Cambridge University Press.

Viciano Pastor, R., y Martínez Dalmau, R., 2012: «Fundamento teórico del nuevo constitucionalismo latinoamericano», en R. VICIANO PASTOR (ed.), Estudios sobre el nuevo constitucionalismo latinoamericano, Valencia: Tirant lo Blanch, 11-49.

VOGENAUER, S., 2015: «Schlüsselwörter in englischen Savigny-Übersetzungen», en J. RÜCKERT y T. Duve (Hrsg.), Savigny, international?, Frankfurt am Main: Vittorio Klostermann, 251-343.

Walz, G. A., 1930: Wesen des Völkerrechts und Kritik der Völkerrechtsleugner, Stuttgart: Kohlhammer.

WeINERT, F., 1982: «Die Arbeit der Geschichte: Ein Vergleich der Analysemodelle von Kuhn und Foucault», Zeitschrift für allgemeine Wissenschaftstheorie, XIII (2), 337-358.

WILHELM, W., 1958: Zum juristischen Methodenlebre im 19. Jahrhundert. Die Herkunft der Methode Paul Labands aus der Privatrechtswissenschaft, Frankfurt am Main: Vittorio Klostermann.

Wyss, U., 1979: Die Wilde Philologie: Jacob Grimm und der Historismus, München: C. H. Beck. Zambrano, M., 1992: El pensamiento vivo de Séneca, 2. ed., Madrid: Cátedra.

ŽižEK, S., El sublime objeto de la ideología, en I. VericAT (trad.), México: Siglo XXI.

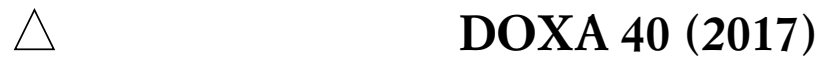

